\title{
Analysis and critical investigation of the financial statements of food sector companies in Thessaly Region (Greece) that were included in the investment development programs the period 2013-2016
}

\author{
Rigas Ioannis ${ }^{1}$, Theodossiou George ${ }^{\uparrow}$, Rigas Nikolaos ${ }^{3}$, Karelakis Christos ${ }^{4}$, Pantos Nikolaos ${ }^{5}$, Goulas Apostolos ${ }^{6}$ \\ ${ }^{1}$ BAIN CAPITAL CREDIT, NPLs Operations (London), United Kingdom \\ ${ }^{2}$ Department of Business Administration, University of Thessaly, GAIOPOLIS, National Road, Larissa-Trikala P.C. 41110, Greece \\ ${ }^{3}$ MBA, KTEL Prefecture of Larissa Programming Department, Greece \\ ${ }^{4}$ Department of Agricultural Development, School of Geotechnical and Forestry Sciences, Democritus University of Thrace, Orestiada, Greece \\ ${ }^{5}$ MBA, TEI of Thessaly, National Road, Larissa-Trikala, P.C. 41500, Greece \\ ${ }^{6}$ Ph.D Candidate, Department of Planning and Regional Development, School of Engineering, University of Thessaly, Greece
}

\begin{tabular}{l} 
ARTICLE INFO \\
\hline Article History \\
Received 25 June 2019; \\
Accepted 20 November 2019 \\
\hline
\end{tabular}

JEL Classifications

F65, G1 1

ABSTRACT

\section{Purpose:}

The aim of this research study is to assess the progress of the food sector companies that received financial aid for investment through the Developmental Laws in the last years (2013-16) of the economic recession in Thessaly Region (Greece), by choosing a random and representative sample of companies.

Design/methodology/approach:

In order to achieve this goal, financial data was collected which would be able to provide us with information in order to study the evolution of the food industry in Thessaly Region (Greece). The statistical analysis of the data was done with the statistical analysis package IBM SPSS Statistics 23. The descriptive statistics on the distributions and frequency diagrams (Histograms) and normal frequencies curves for the percentages of changes were also calculated. To test the significance of the differences between the mean values of the financial statements items, the method of One-Way Analysis Of Variance (One-Way ANOVA) was used. The same method was used to test the mean values of both the changes in amounts and in their percentages.

\section{Findings:}

In short, we can say that the percentage changes in Total Assets and Equity the time period 2013-16 are small and concentrated around zero. The same period, we have a

Keywords:

Investment,

financial analysis,

financial statement items,

Food Industry, Thessaly

Region (Greece) significant increase in L/M Debt and Sales, except for a few extreme cases, while the percentage changes in Gross Profit and Profit before Tax are limited. The year 2016 there were significant changes in Taxes and Net Profit from AM2005-16.

Research limitations/implications:

The collection, processing, and analysis of the financial data of the undertakings were limited to the undertakings which have the obligation to publish their financial data. Originality/value:

In recent years, very few studies have been carried out on the effectiveness of investment by private companies subsidized by Greek or European Investment Programs.

\section{Introduction}

Food sector is one of the most important branches of secondary production (processing) in Greece today, due to its large contribution to turnover (sales), employment, the number of manufacturing enterprises, support to primary production, added value and to the country's growth in general (Chatzitheodoridis F., et al. 2016; Kontogeorgos et al.2017).

${ }^{\dagger}$ Corresponding Author: Theodossiou George

e-mail: geortheo@uth.gr 
According to Foundation For Economic \& Industrial Research (2018), the food industry has been and continues to be one of the most dynamic, outward-looking and competitive sectors of the Greek economy, with strong investment and commercial activity in Greece, Balkans, and Europe. In terms of sales and employment both in Greece and at the level of the European Union, it is the most important sector, reaching $65-70 \%$ of the turnover in recent years. The food industry combined with the tourism industry has been the mainstay of the Greek economy for the past decade, supported and helped the growth of Greek agriculture and its extroversion and contributed to tackling the economic crisis and leaving the country out of the status of the memorandums.

The phenomenon of the emergence and growth of red loans (NPLs) after the financial year 2008 was an important stimulus for us to study, analyze and conclude how the major industry of the Greek industry was affected by the restrictive and rigorous financing policy Greek credit system (Louzis et al., 2012). NPLs have had a significant impact on the macroeconomic factors (macroeconomic variables) of the country (GDP, employment, interest rates, public debt, etc.) (Saba, I., 2012) and have significantly affected all sectors of the Greek economy (Stournaras, 2018). On the occasion of this event, we decided to address the food industries of Thessaly Region choosing a random and representative sample of 70 enterprises, from these that have been included in development programs, and to study the course, evolution and changes of selected financial statements items for four consecutive years (2013-16) and to consider as a further study their changes from the AM 2005-16.

The aim of the present study is to analyze and interpret the evolution of representative financial statements items of the food in Thessaly Region during the last years (2013-2016) of the economic recession in Greece. The selection of the 70 sample companies for the study was based on the following conditions:

- Their available financial data must be sufficient to enable the financial data to be compared between them.

- Companies belonging to the same activity code STAKOD 10 (Food Industry).

- Companies not to be established but to have ongoing economic activity and to have the legal form of the Societe Anonyme or the Limited Liability Company.

- The size of the companies to be such (Small, Medium, Large) to ensure the plurality of the sample.

- The type of companies' activity is different (dairy, meat products, olive groves, fish, etc.).

- The choice to be random and representative of the type of companies' activity.

- The integration of companies into investment programs

\section{Literature Review}

From the literature review, the role of investment incentives to reduce territorial disparities is a central issue of regional science (Glaeser and Edward, 2001; Gabe and Karybill, 2002; Harris and Trainor, 2005). There is, however, no agreement on the effectiveness of investment incentives, mainly because one should evaluate the same investments without subsidies, which is practically difficult. Some studies show that regional capital incentives can cause additional investment in subsidized enterprises (Daly et al., 1993;

Other research shows that the effect of subsidies on efficacy and productivity seems negligible or negative (Lee, 1996; Harris and Trainor, 2005; Criscuolo et al., 2009). The impact of capital subsidies on employment is also questionable (Gabe and Kraybill, 2002). Carlucci and Pellegrini (2005) present an empirical indication of a positive impact on employment, using different parametric and non-parametric approaches.

Policymakers prefer to subsidize programs with higher employment, even if they are less productive (Bronzini and Blasio, 2006). In one study, Schalk and Untied (2000) report that the incentives for regional investment in Germany, unlike other countries, have been successful in both the investment and employment objectives. However, the question remains whether the policy is also effective in relation to the regional income convergence objective in their own country. Similar findings have been made in Daly et al (1993) in Canada where it was found that tax incentives to invest in capital are not the most effective way to stimulate employment.

In Greece, there has been great difficulty over time in assessing the impact of investment incentives in Developmental Laws on companies. In no investment law, there was no provision for the collection of data referring to the performance of enterprises before and after their affiliation to the Law (Parliament of the Hellenic Republic, 2016). In the explanatory memorandum of the last-mentioned Development Law 4399/16, it is stated that the bases of the previous laws have been linked to external business information data, in order to ascertain the real impact of the inclusion of the enterprises in the benefits of the Investment Law. The only data published was that the ratio of the return on equity to the assessment of the effectiveness of the aid was used for hotels and industrial enterprises that had been included in L.2601/98, without specifying the sample number.

During the implementation of the Development Laws in Greece over the period 1994-2014, the investment amounting to EUR 38 billion amounted to $13.2 \%$ of the total gross private sector (non-residential) capital of the corresponding period (Explanatory Statement of U.S. Patent 4,399,16). It is clear, therefore, that State aid incentives can help boost investment activity, but it is not in itself a sufficient investment support factor. At the cost of creating new jobs, we see that average investment costs and average subsidies show a very large increase. Interpretation of these results is difficult because there is no evidence of the type and characteristics of the new jobs created and whether they involve low or highly skilled employment and pay.

The average time for realization and disbursement of the completed investments of AN 3299/04 in Thessaly was 46.4 months, approaching 4 years. $(\min =170$ days, $\max =2,868$ days), (Germanoloudis, 2017). 
The economic stability of a country providing its citizens with the potential and security of investment and business openings (Norman and Ranciere, 2006). However, economic instability in a country leads to wage and pension cuts, as well as a large increase in unemployment and a reduction in consumption. The inability to finance from other sources shrinks the private sector of the economy.

Entrepreneurship is inextricably linked to productive activity and growth, which is seen as a necessary condition for overall and social development, such as growth in production, income, employment, exports, etc (Dias et al., 2019). Enterprises in the effort to grow, to become competitive and to survive in an uncertain economic environment, are forced to invest. The economic crisis has negatively affected the Greek economy, especially since 2009, after the crisis has deteriorated dramatically (Artelaris, 2017; Economic Bulletin, 2018). The financial crisis affects domestic economic activity because the tightening of criteria for credit to businesses and households limits liquidity (Cabral, R., Castellanos-Sosa, 2019). At the same time, the significant weakening of business and household expectations leads to a reduction in the momentum for consumption and to the risk of a decline in business investment. As a result, demand for credit is reduced by both households and businesses (Bank of Greece, 2009).

The economic crisis has clearly left its mark and has affected to a greater or lesser extent the overwhelming majority of the productive sectors of the domestic economy. Small and medium-sized enterprises that are the backbone of the national economy are the ones that have suffered the greatest blow. Between 2008 and 2014, 200,000 medium-sized businesses, which were essentially commercially active, ceased to operate and this represents a reduction of 25\% (Manifava, 2015; Voumvaki, 2018; Ikonomou, 2018).

The Greek food industry is one of the most important sectors of the Greek economy, it contributes significantly to employment, turnover, and growth, while developments in the sector usually affect the whole of Greek manufacturing (Loizou, et al. 2019; SEV, 2017; Polychronidou, et al. 2016). In 2009, when the country's recession began, the sector suffered a heavy blow to employment, added value, sales, etc. However, this decline comes mainly from smaller companies (under 10), which are also the vast majority, both in the Food sector (95\%) and in the Drinks sector (90\%). At the same time, the sector as an integral part of the agri-food chain is directly affected, but it also affects the other sectors of activity (primary and tertiary) to a significant extent, with corresponding consequences for the entire national economy (Foundation for Economic and Industrial Research, 2011)

The food industry can contribute to the growth of the Greek economy and establish both Greek branded products and the Mediterranean diet in international markets. (Foundation For Economic \& Industrial Research (IOBE) 2018; Mattas, et al., 2006). The main reason for the development of the food industry was the increase in tourism and the improvement in living conditions that led to an increase in demand. During the interwar period the food industry was second in the Greek manufacturing sector after the textile industry and started to grow from the middle of the second half of the 20th century until the end of the same century, Chekimoglou, Roupa, 2006; Foundation for Economic \& Industrial Research (IOBE, 2018.). More specifically, the food industry in Greece accounts for $21.2 \%$ of all Greek processing enterprises and is ranked first among the processing industries. The annual growth rates of the turnover of the food and beverage processing sector, the number of employees and the number of enterprises in Greece are noteworthy in a time of crisis (Foundation For Economic \& Industrial Research (2018). As mentioned, among other things, in the report, the percentages of change in the key structural indicators of the domestic food industry in 2014 compared to 2013 indicate a marginal increase in the number of enterprises in the sector, as opposed to total processing, where the number of enterprises fell by $2 \%$. A positive change in the number of enterprises is also recorded in the Drinks sector $(2.4 \%)$. However, a significant drop was recorded in terms of gross value added in Food $(-5 \%)$, but significantly lower than in the whole manufacturing sector $(-13 \%)$.

At the European Union level, (E.U. Food Drink Europe, 2015), the food industry is the number one in manufacturing employment in the European Union, employing about 5 million people, which translates into $16 \%$ of the total number of workers in European industry and that it accounts for $13 \%$ of all European manufacturing firms).

The food and beverage industry in Greece faces a number of international challenges related to competition, as well as various problems stemming from the Greek reality as it has been shaped in recent years. Strong changes, in social institutions, economic issues, technological developments at the international level, the industry has to face a number of problems (Foundation for Economic and Industrial Research (2011), such as:

- Changes created by the economic conjuncture and its impact, which strongly affects consumer habits and consumer incomes.

- The decline in consumer purchasing power, which has led consumers to choose private label products as opposed to branded products.

- $\quad$ The reduced liquidity faced by several businesses and the reduction in bank lending have resulted in depleted corporate capital and low money mobility.

- The inadequate institutional framework and bad debts in relation to inefficient public administration have greatly reduced the climate for trade.

- Reduced investment, transportation problems and low credit limits from foreign suppliers have created several difficulties in producing products and have increased the cost of producing them.

According to the FAO, the challenges faced by the industry internationally are diverse and numerous, such as:

- Sustainable improvement in agricultural productivity to meet rising demand

- Ensuring a sustainable natural resource base

- Tackling climate change and intensifying physical risks

- Eliminate extreme poverty and reduce inequality

- Eliminating hunger and all forms of malnutrition 
- Creating efficient food systems, inclusive and more resilient

- Improving income opportunities in rural areas and tackling the root causes of migration

- Building resilience to prolonged crises, disasters, and conflicts

- $\quad$ Preventing cross-border and emerging threats to agriculture and food

- Address the need for coherent and effective national and international governance. (FAO, 2017).

From this point of view, the necessity of adapting the sector's enterprises to new data and rapid developments becomes necessary. Businesses need to adapt to the combination of quality, healthy Mediterranean food and fast food, the production and marketing of organic products, and the new food trends that meet consumer demands (Stratou A., 2013).

\section{Data and Methodology}

In this paper, we have attempted to assess the evolution of the Food sector in Thessaly Region the recent years (2013-16) of the economic recession in Greece. For this purpose, data were collected to provide us with information to create a global image of the evolution of the sector's companies in Thessaly Region-

\section{a. Data collection}

The data come from the financial statements of Food sector companies of Thessaly Region, which were included in development programs, and were drawn by ELSTAT (http://www.statistics.gr). The collection and processing of the economic data of a representative sample of 70 food sector companies of Thessaly Region (Greece), was carried out with a view to analysing in detail their economic evolution over the four-year period 2013-2016. The selection was done in a random and representative way, so that companies of different sizes (small, medium, large) and capacity were included, with the aim of extracting as reliable as possible conclusions.

\section{b. Descriptive statistics and distribution of the data}

Statistical analysis of the data was done with the statistical analysis package IBM SPSS Statistics 23. The descriptive statistics (mean, standard error, standard deviation, and confidence interval) for the distributions: a) of the amounts of financial statements items for the years 2013-2016 and the AM 2005-16; b) of the changes of the items between the years 2013-14, 2015-14, 2016-15 for both amounts and percentages and c) of the changes of the items for the years 2013, 2014, 2015 and 2016 from AM 2005-16 also for both the amounts and percentages thereof, were calculated. Moreover, histograms and the corresponded normal curves of the percentage changes of the items for the years periods 2013-14, 2015-14, 2016-15, as well as for the percentage changes of the items for the years 2013, 2014, 2015 and 2016 from the AM2005-16 were calculated.

\section{c. One-Way Analysis of Variance (One-Way ANOVA)}

In order to check the significance of the differences between the mean values of the amounts of financial statements items for the years 2013-2016 and the AM 2005-16, the method of one-way ANOVA was used. The oneway analysis of variance (ANOVA) is used to determine whether there are any statistically significant differences between the means of more than two independents (unrelated) groups (it used when there is a minimum of three groups). The same method was used to test the mean values of the items changes between the years 2013-14, 2015-14, 2016-15 for both amounts and percentages as well as for testing the mean values of the items changes for the years 2013, 2014, 2015 and 2016 from AM2005-16 also for both the amounts and percentages thereof.

\section{Results and Discussion}

\section{a. Descriptive statistics and item distributions}

The histograms and the corresponded normal curves of the percentage changes of the items between the years 2013-14, 2015-14, 2016-15, as well as for the percentage changes of the items for the years 2013, 2014, 2015 and 2016 from the AM2005-16 are shown in Figures 1-9. It can be deduced from the Figures that the actual frequency curves for the distribution of the nine-item are almost normal curves (Figures 1-9) with slight variations in the shape of the curves (narrow curves, flat curves). So we have the picture for each element:

\section{Total Assets}

a.

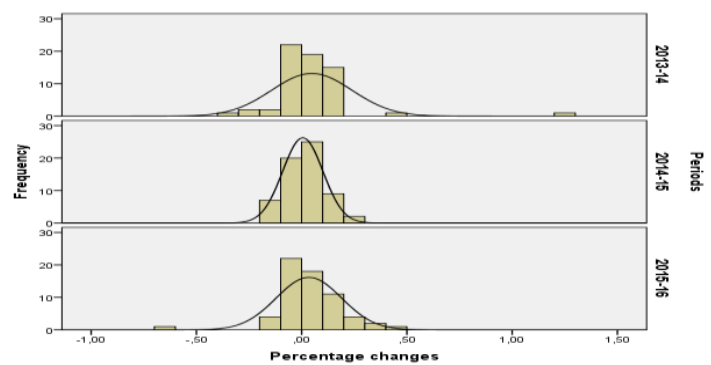

b.

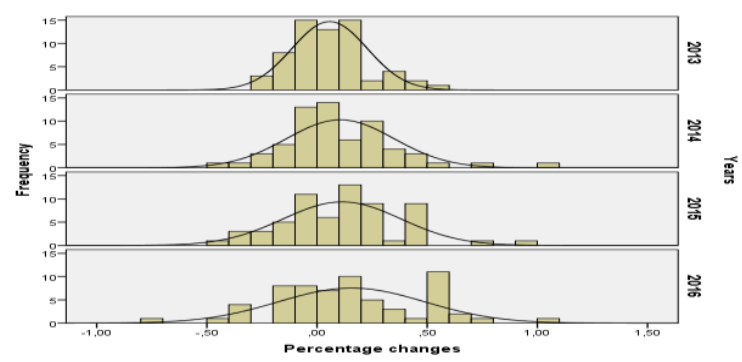

Figure 1.a. Histograms and normal curves of the percentage changes of the Total Assets the time periods 2013-14, 2014-15, 2015-16. b. Histograms and normal curves for the percentage changes of the Total Assets for the years 2013, 2014, 2015 and 2016 from the AM2005-16. 
Figure 1a shows that the percentage changes curve for 2014-15 is much narrower than the other two. This means that the changes in Total Assets in this period (2014-15) are small and concentrated around zero. The other two appear more flattened with outliers (extreme values), especially for the period 2013-14. This is due to the doubling of the Total Assets of a large company.

From Figure 1b we have that for the curves of the percentage changes in Total Assets the years 2013-16 from AM2005-16 the curvature is decreasing with less normality and accompanied by the appearance of outliers. This means that many companies from 2014 onwards and mainly in 2016 have experienced significant changes in Total Assets.

\section{Fixed Assets}

a.

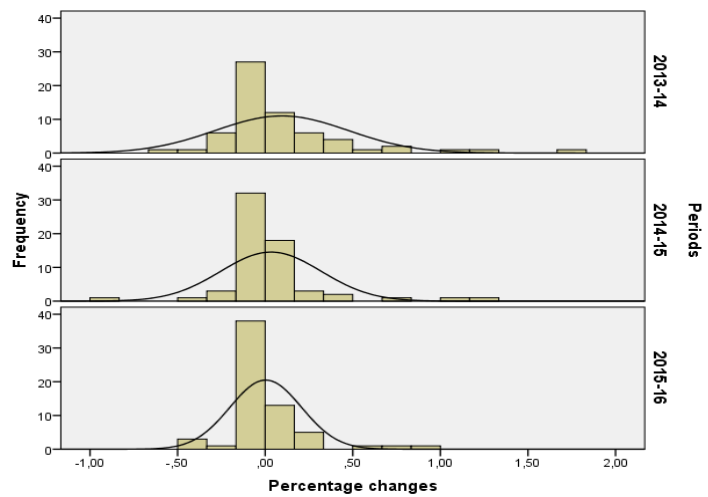

b.

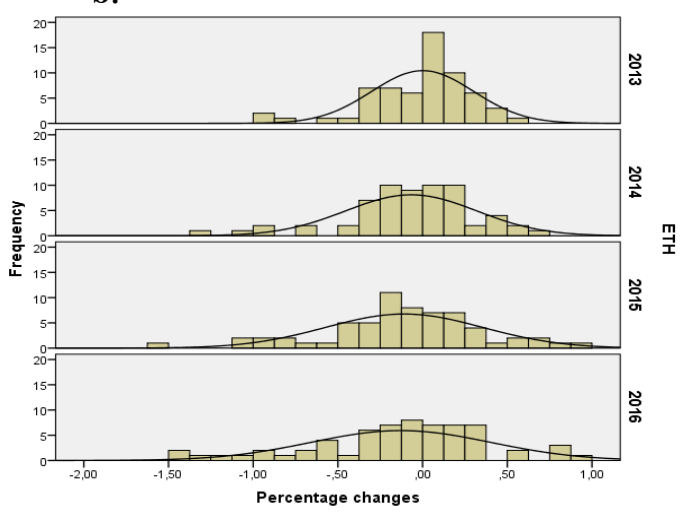

Figure 2.a. Histograms and normal curves of the percentage changes of the Fixed Assets the time periods 2013-14, 2014-15, 2015-16. b. Histograms and normal curves for the percentage changes of the Fixed Assets for the years 2013, 2014, 2015 and 2016 from the AM2005-16

From Figure 2.a we can see that the percentage changes curve for the period 2015-16 is slightly more narrow than the other two, the variables of which are more dispersed with outliers, especially for the period 2013-14. From Figure 2.b we have that for the curves of the percentage changes in Total Assets the years 2013-16 from AM2005-16 the curvature is decreasing with the variance increasing and accompanied by the appearance of outliers.

\section{Equity}

a.

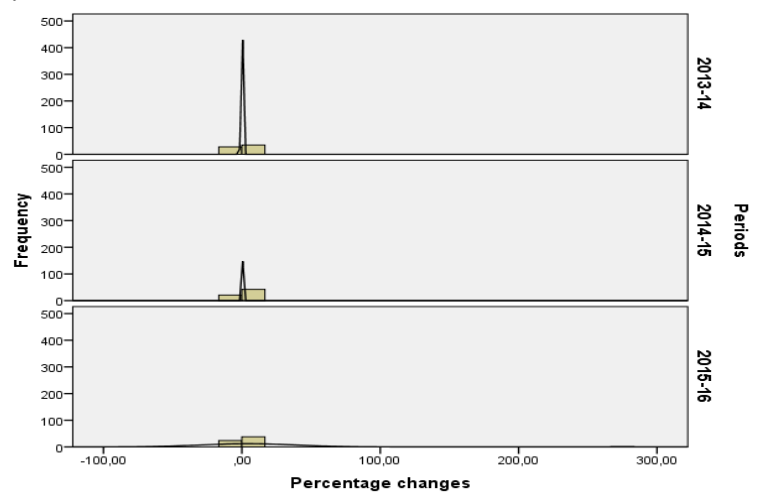

b.

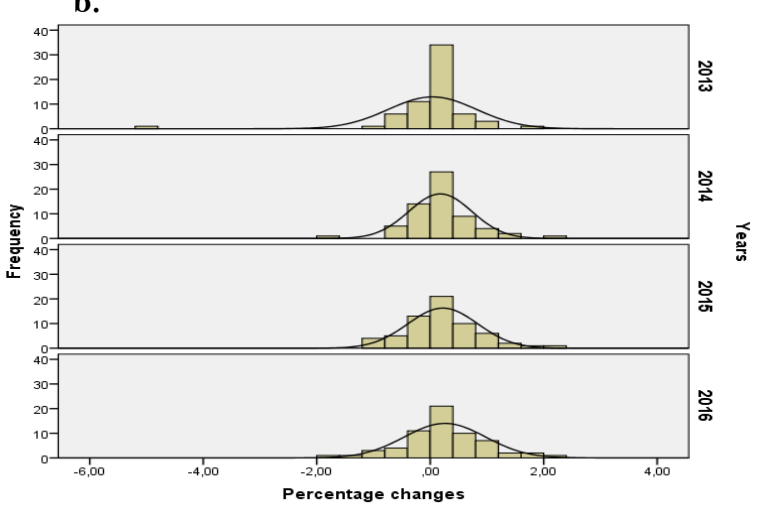

Figure 3.a. Histograms and normal curves of the percentage changes of the Equity the time periods 2013-14, 201415, 2015-16. b. Histograms and normal curves for the percentage changes of the Equity for the years 2013, 2014, 2015 and 2016 from the AM2005-16

From Figure 3.a we see that the percentage change curves for the 2013-14 and 2014-15 intervals are quite narrow with the values of the variables being concentrated around zero, while the third (2015-16) are quite flat asymmetrical to the right with a significant outlier. This is due to the fact that in this period the Equity of a company increased by 275.23\%. From Figure 3.b we have that for the curves of the percentage changes of Equity the years 2013-16 from AM 2005-16 the curvature is approximately the same with the curves to show significant normality. Smaller normality is shown by the 2013 variable showing a significant outlier $(-5.16)$. 


\section{Long/Medium-term Debt}

a.

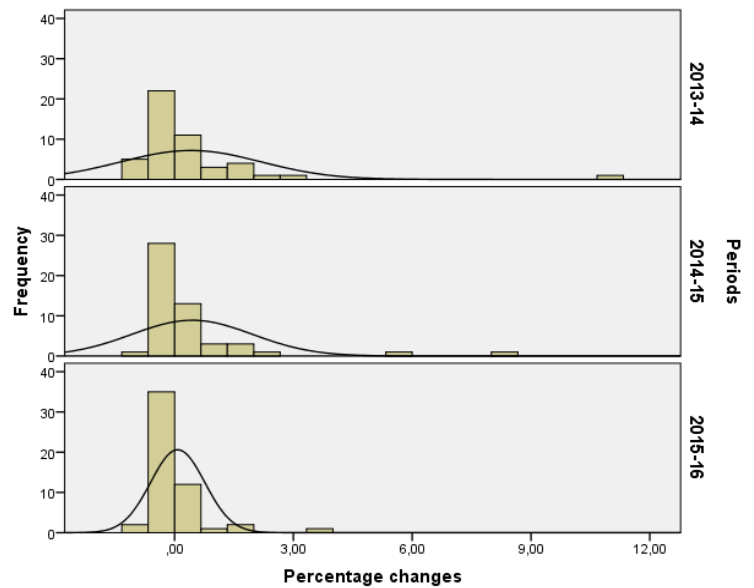

b.

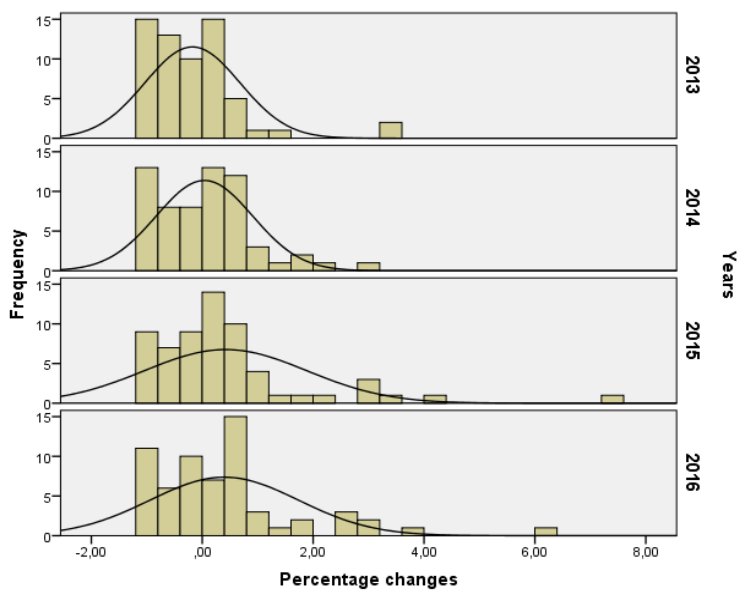

Figure 4.a. Histograms and normal curves of the percentage changes of the L/M Debt the time periods 2013-14, 2014-15, 2015-16. b. Histograms and normal curves for the percentage changes of the L/M Debt for the years 2013, 2014, 2015 and 2016 from the AM2005-16

From Figure 4.a we can see that the curve of the percentage changes in L/M Debt for the period 2015-16 is narrower than those of the other two percentage changes and shows some normality. The other two appear quite flat with right asymmetry and outliers. This means that in 2013-15 we had a significant increase in L/M debt for some companies. Figure 4.b shows that curvature is decreasing from 2014 onwards, accompanied by an increase in right asymmetry and outliers. This is due to the fact that some companies significantly increased the L/M Debt compared to the AM2005-16.

\section{Sales}

a.

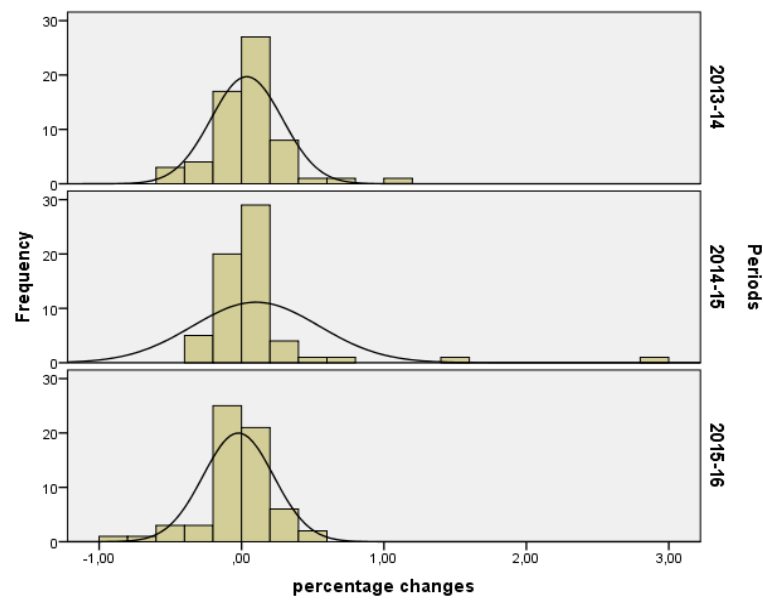

b.

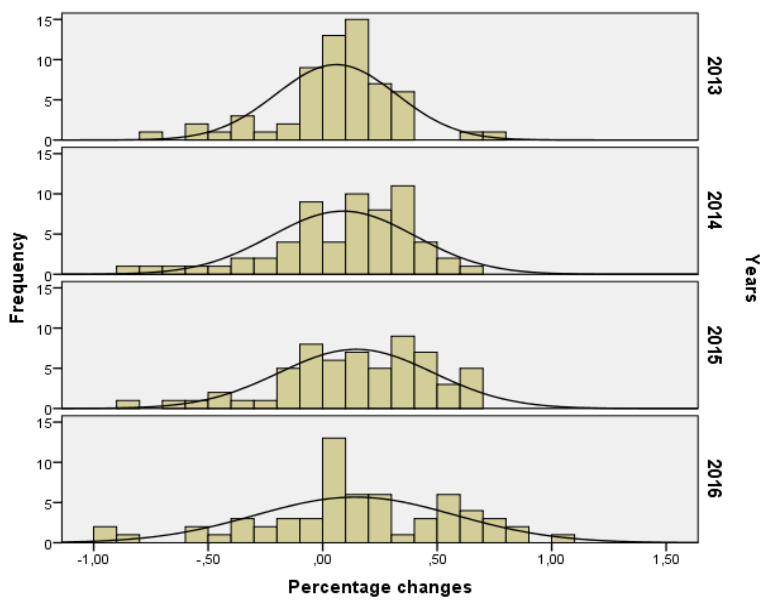

Figure 5.a. Histograms and normal curves of the percentage changes of the Sales the time periods 2013-14, 2014-15, 2015-16. b. Histograms and normal curves for the percentage changes of the Sales for the years 2013, 2014, 2015 and 2016 from the AM2005-16

From Figure 5.a we can see that the percentage changes in Sales of the time periods 2013-14 and 2015-16 are narrow and show significant normality. This means that Sales changes for these two time periods show a regularity centred around zero. The Sales percentage changes curve in 2014-15 is flat, present right asymmetry and outliers, which is translated to a significant increase in Sales in 2014-15 for some companies. Figure 5.b shows us that the curvature and normality of the percentage changes in Sales curves in the years of the period 2013-16 from the AM2005-16 are decreasing, with slight left asymmetry. This means that there are bigger changes in Sales of some companies and even to the worst as long as we go up the year's scale. 


\section{Gross profit}

a.

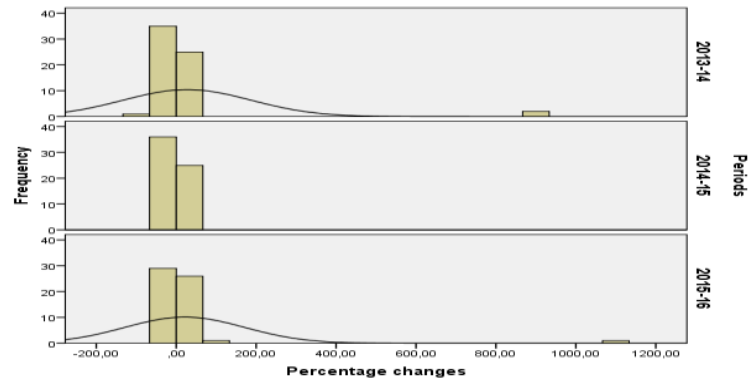

b.

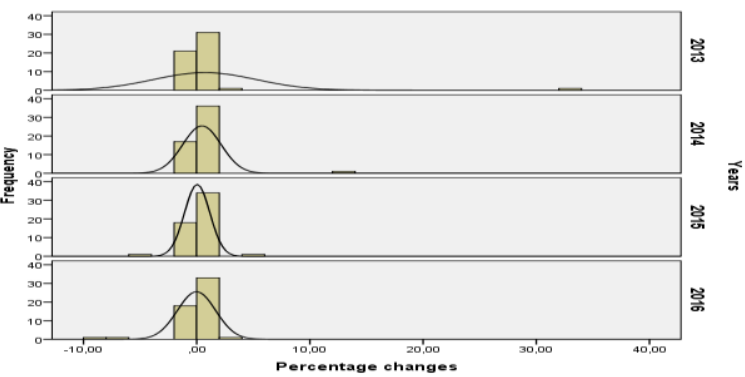

Figure 6.a. Histograms and normal curves of the percentage changes of the Gross profit the time periods 2013-14, 2014-15, 2015-16. b. Histograms and normal curves for the percentage changes of the Gross profit for the years 2013, 2014, 2015 and 2016 from the AM2005-16.

Figure 6.a informs us that the percentage changes in Gross Profit for the three periods show almost the same image with a concentration around zero. A major change presents the variable in the period 2013-14 in which a company showed a Gross Profit increase of $-9567 \%$ (from -3 to 284 ).

About the same image is shown in Figure 6.b where the percentage changes in the Gross Profit of the years of the period 2013-16 from MO2005-16 are almost similar with a concentration around zero and limited positive extreme changes for the years 2013 and 2014.

\section{Profit before Tax}

a.

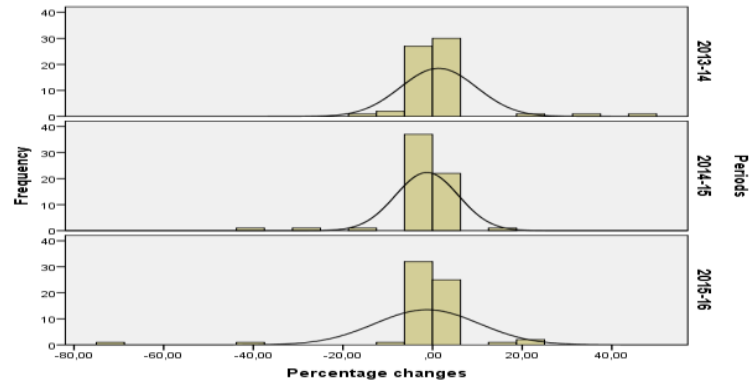

b.

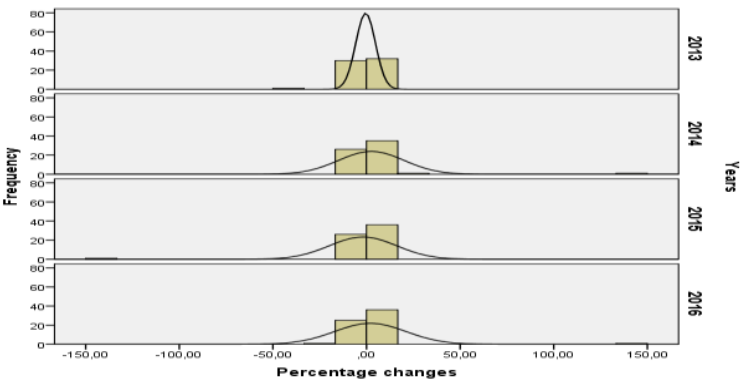

Figure 7.a. Histograms and normal curves of the percentage changes of the Profit before Tax the time periods 201314, 2014-15, 2015-16. b. Histograms and normal curves for the percentage changes of the Profit before Tax for the years 2013, 2014, 2015 and 2016 from the AM2005-16.

An almost similar picture to Gross Profit shows the percentage changes in Profit before Tax the time periods 2013-14, 2014-15, 2015-16 (Figure 7.a) as well as the percentage changes in the Profit before Taxes the years of the period 2013-16 from the average AM2005-16 (Figure 7.b ). The only difference is that the percentage changes in Profit before Tax between the years of the period 2013-16 present some outliers and that the percentage changes in Profit before Tax of the year 2013 from AM2005-16 are restricted to a small area of zero (narrow curve).

\section{Taxes}

a.

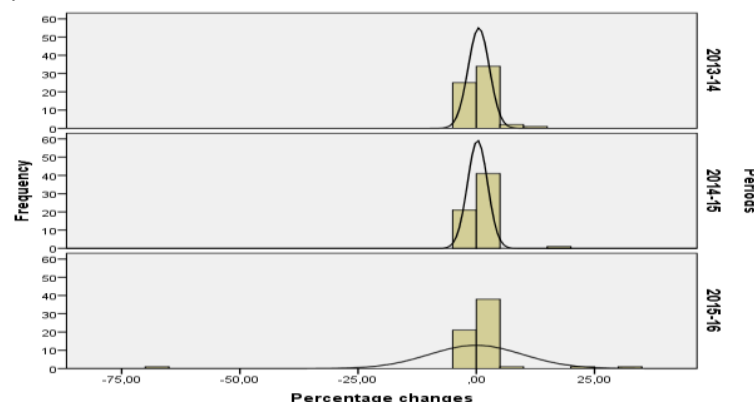

b.

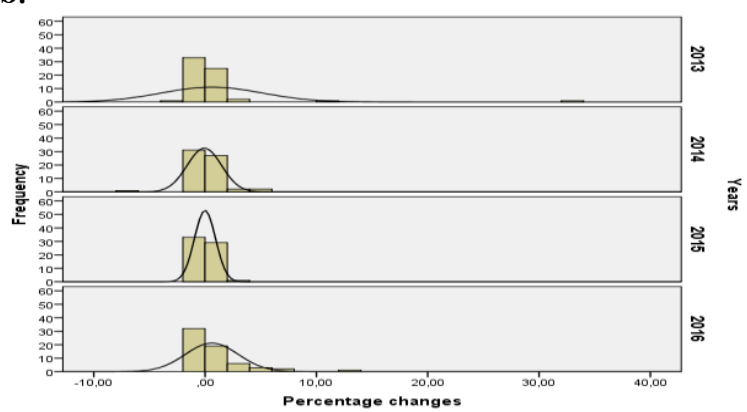

Figure 8.a. Histograms and normal curves of the percentage changes of the Taxes the time periods 2013-14, 2014-15, 2015-16. b. Histograms and normal curves for the percentage changes of the Taxes for the years 2013, 2014, 2015 and 2016 from the AM2005-16

The percentage changes in taxes the time periods 2013-14, 2014-15,2015-16 show a similar picture to that of Profit before Tax (Figure 8.a). The only difference is that the curves of the percentage changes in taxes for the periods 2013-14 and 2014-15 are quite narrow, ie the changes in taxes from 2013 to 2014 and from 2014 to 2015 are virtually 
nil. The curve from 2015 to 2016 appears quite flat, which means that there are significant changes in the relevant taxes in 2016. The percentage of changes in taxes for the years of the period 2013-16 from AM2005-16 (Figure 8.b) shows a marked difference between them. Percentage changes in taxes are fairly small in 2015 and slightly higher in 2014. In 2013, we have large positive and negative deviations (a flat curve) and 2016 a significant increase in proportionate taxes (right asymmetry).

\section{Net Profit after taxes}

a.

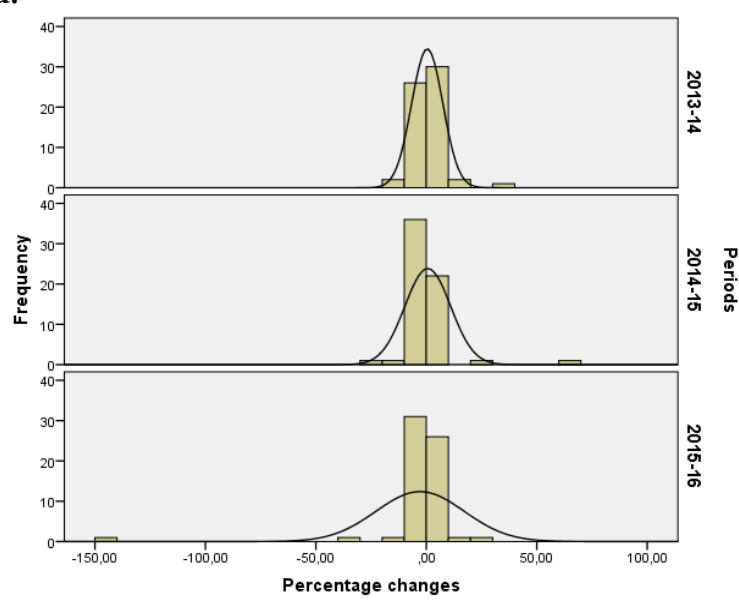

b.

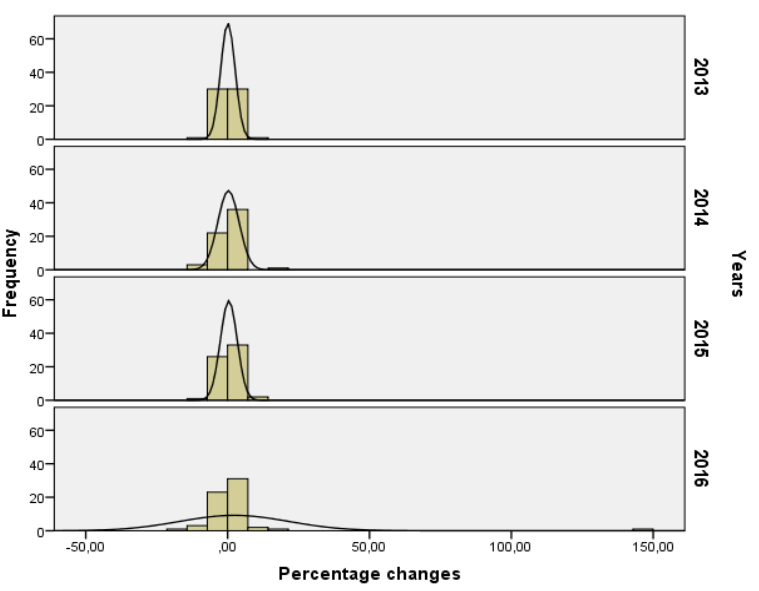

Figure 9.a. Histograms and normal curves of the percentage changes of the Net Profit after taxes the time periods 2013-14, 2014-15, 2015-16. b. Histograms and normal curves for the percentage changes of the Net Profit after taxes for the years 2013, 2014, 2015 and 2016 from the AM2005-16

Almost the same picture as that of Taxes shows the percentage changes in Net Profit after taxes the time periods 2013-14, 2014-15, 2015-16 (Figure 9.a). The curve of percentage changes in Net Profit after taxes in the period 201516 shows lower curvature than the other two, which means greater differentiation in net profit. In addition, the 201415 period the curve shows a slight right asymmetry, which translates into a small increase in Net Profit. From Figure 9.b we have that curves of the percentage changes in Net Profit after taxes of the years 2013, 2014 and 2015 from AM2005-16 are quite narrow and concentrated around zero. This means that the changes in Net Profit after taxes in these years were quite limited. The curve of the year 2016 is quite flat with an extreme value to the left. This means we have significant changes in Net Profit after taxes in several companies, both positive and negative. The extreme value comes from the change in the Net Profit after taxes of a company from -1 to -148 .

\section{b. One-way ANOVA}

In order to check the significance of the differences between the mean values of the amounts of financial statements items for the years of the time interval 2013-2016 and the AM2005-16, and the AM2005-16, the method of one-way ANOVA was used. The same method was used to test the mean values of the items changes the time periods 2013-14, 2014-15, 2015-16 for both amounts and percentages as well as for testing the mean values of the items changes of the years 2013, 2014, 2015 and 2016 from AM2005-16 also both for amounts and percentages thereof. The most important assumptions that the data must meet in order a one-way ANOVA to give a valid result are: a) there should be no significant outliers, b) the dependent variable should be approximately normally distributed for each category of the independent variable and c) there needs to be homogeneity of variances.

When analyzing data using SPSS Statistics, usually one or more of these assumptions is violated. This is not uncommon when working with real-world data, but it is acceptable the use of the one-way ANOVA when the conditions are met approximately. From the Histograms and the normal curves of the amounts of financial statements items for the years 2013-2016 and the AM2005-16, of the items changes between the years 2013-14, 2015-14, 201615 for both amounts and percentages and of the items changes of the years 2013,2014, 2015 and 2016 from AM200516 also both for amounts and percentages we see that the two first assumption are approximately satisfied. For the third assumption, we have the Levene's test for homogeneity of variances in SPSS Statistics. The application of the One-Way Analysis of Variance in the financial statements items showed:

\section{The test of Homogeneity of Variances of the Total Assets}

The test of Homogeneity of Variances of the Total Assets for the years of the time period 2013-16 and the AM2005-16 showed that there are no significant differences between the variances of the five variables (or groups) of the amounts of Total Assets (Levene Statistic = 0.293, Sig. = 0.882). The one-way ANOVA showed that there are no statistically significant differences between the mean values of the five variables $(F=0.127$, Sig. $=0.973)$. Figure 10 gives the profile plot of the mean values of the five variables. 


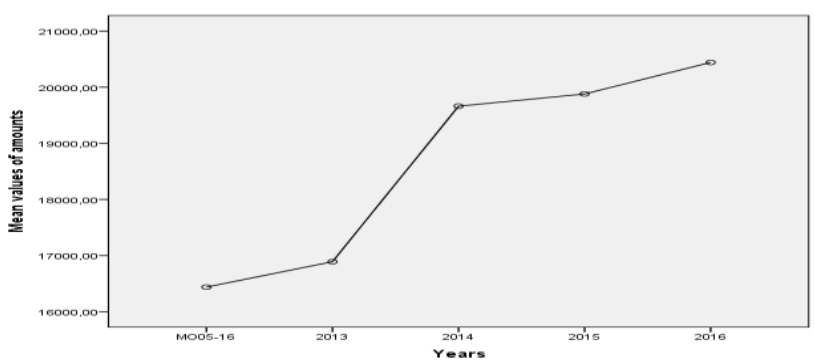

Figure 10. Profile plot of the mean values of the amounts of Total Assets the years of the period 2013-16 and of the AM2005-16.

The test of Homogeneity of Variances of the changes of the Total Assets in the time periods 2013-14, 2014-15 and 2015-16 showed that there are no significant differences between the variances of the three variables both for the changes in amounts and in percentages, $($ Levene Statistic $=1.620$ Sig. $=0.201)$ and $($ Levene Statistic $=2.705$ Sig. $=$ 0.069) respectively. The one-way ANOVA showed that there are no statistically significant differences between the mean values of the three variables for both the changes in amounts and percentages, $(\mathrm{F}=1.295$, Sig. $=0.276)$ and $(\mathrm{F}$ $=0.848$, Sig. $=0.430)$ respectively. Figure 11 gives the profile plots of the mean values of the three variables (a) for amounts and (b) for percentages.

a.

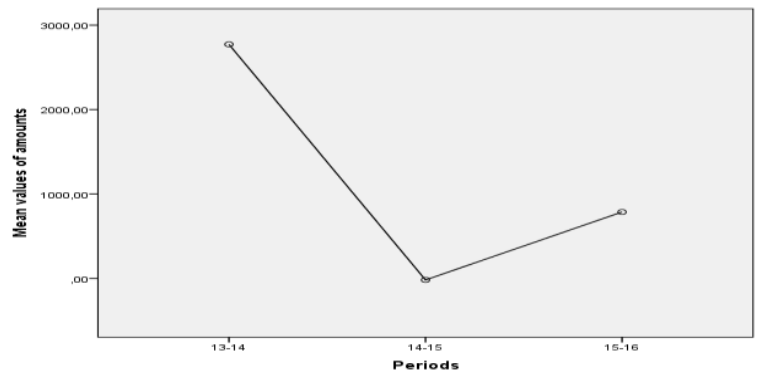

b.

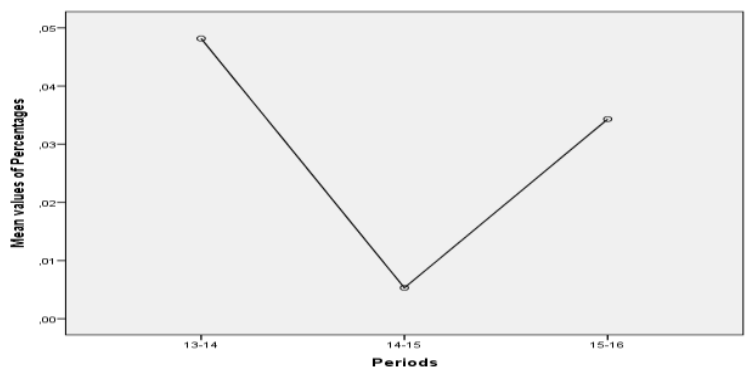

Figure 11. Profile plots of the mean values of the changes of the Total Assets the time periods 2013-14, 2014-15 and 2015-16 (a) in amounts and (b) in percentages.

The test of Homogeneity of Variances of the changes of the Total Assets for the years of the time period 2013-16 from the AM2005-16 (four variables) showed that there are no significant differences between the variances of the amounts changes (Levene Statistic $=1.114$, Sig. $=0.344$ ) but the variances in percentage changes differ (Levene Statistic $=6.965$, Sig. $=0.000)$. The one-way ANOVA showed that there are no statistically significant differences between the mean values of the four variables for both the changes in amounts and in percentages, $(\mathrm{F}=0.525$, Sig. $=$ 0.666 ) and $\mathrm{F}=1.533$, Sig. $=0.206$ ) respectively. Since the post hoc test for variables with different variances (GamesHowell test) showed that the mean values of the four variables do not differ by two, we can accept the results of the variance analysis. Figure 12 gives the profile plots of the mean values of the four variables (a) for amounts and (b) for percentages.

a.

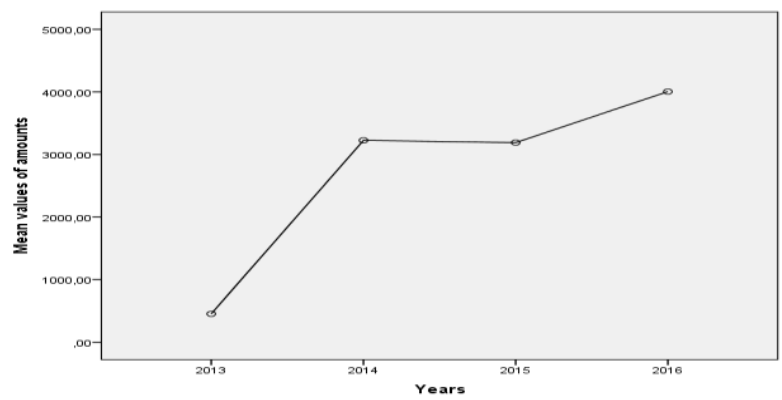

b.

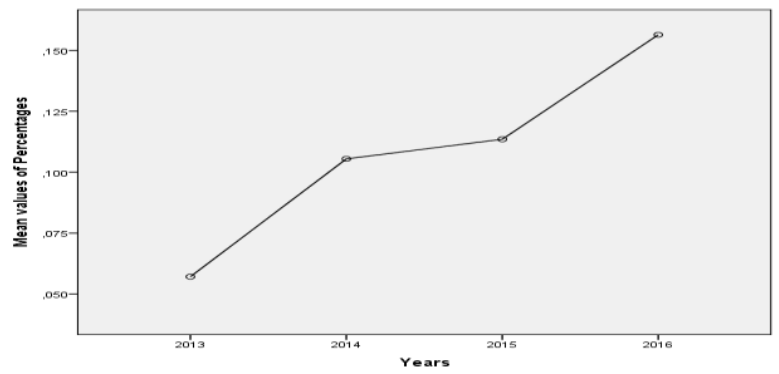

Figure 12. Profile plots of the mean values of changes of Total Assets the years of the period 2013-16 from AM200516 (a) in amounts and (b) in percentages.

\section{The test of Homogeneity of Variances of the Fixed Assets}

The test of Homogeneity of Variances of the Fixed Assets for the years of the time period 2013-16 and the AM2005-16 showed that there are no significant differences between the variances of the five variables (or groups of the amounts of Fixed Assets) (Levene Statistic $=0.198$, Sig.=0.939). The one-way ANOVA showed that there are no statistically significant differences between the mean values of the five variables $(\mathrm{F}=0.071$, Sig.=0.991). Figure 13 gives the profile plot of the mean values of the five variables. 


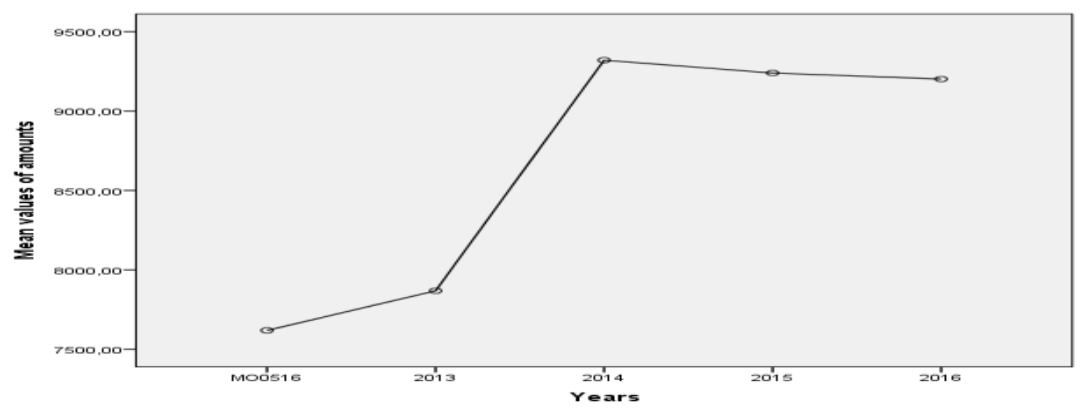

Figure 13. Profile plot of the mean values of the amounts of Fixed Assets the years of the period 2013-16 and of the AM2005-16.

The test of Homogeneity of Variances of the changes of the Fixed Assets in the time periods 2013-14, 2014-15 and 2015-16 showed that there are significant differences between the variances of the three variables both for the changes in amounts and in percentages, (Levene Statistic $=3.075$ Sig.=0,49) and (Levene Statistic = 5.254 Sig.=0.006) respectively. Since the post hoc test for variables with different variances (Games-Howell test) showed that the mean values of the three variables do not differ by two, we can accept the results of the one-way ANOVA, which shows that the mean values of the three variables do not differ significantly for both the changes in amounts and in percentages, $(\mathrm{F}=1.043$, Sig. $=0.355$ and $\mathrm{F}=1.527$, Sig. $=0.220)$ respectively. Figure 14 gives the profile plots of the mean values of the three variables (a) for amounts and (b) for percentages.

a.

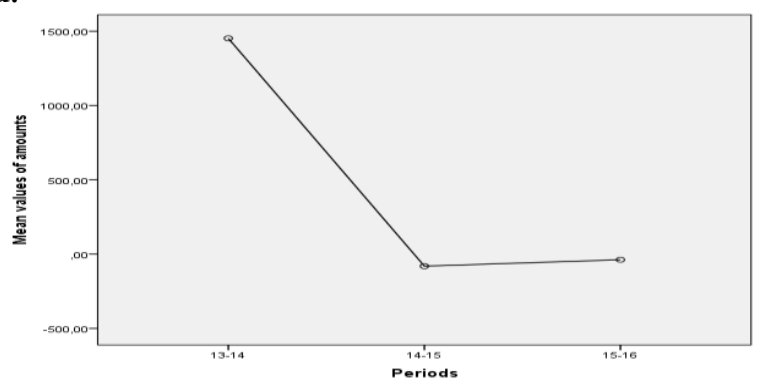

b.

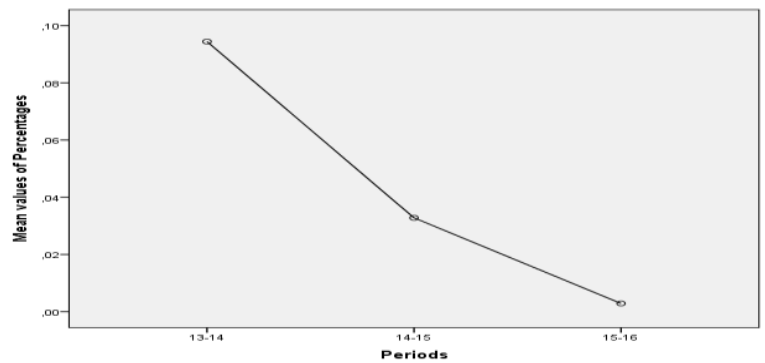

Figure 11. Profile plots of the mean values of the changes of the Fixed Assets the time periods 2013-14, 2014-15 and 2015-16 (a) in amounts and (b) in percentages.

The test of Homogeneity of Variances of the changes of the Fixed Assets for the years of the time period 2013-16 from the AM2005-16 (four variables) showed that there are no significant differences between the variances of the amounts changes (Levene Statistic $=0.908$, Sig. $=0.438$ ) but the variances in the percentage changes differ $($ Levene Statistic $=4.329$, Sig.=0.005). The one-way ANOVA showed that there are no statistically significant differences between the mean values of the four variables for both the changes in amounts and in percentages, $(\mathrm{F}=0.285$, Sig. $=0.836$ ) and $F=1.115$, Sig. $=0.344$ ) respectively. Since the post hoc test for variables with different variances (Games-Howell test) showed that the mean values of the four variables do not differ by two, we can accept the results of the variance analysis. Figure 15 gives the profile plots of the mean values of the four variables (a) for amounts and (b) for percentages.

a.

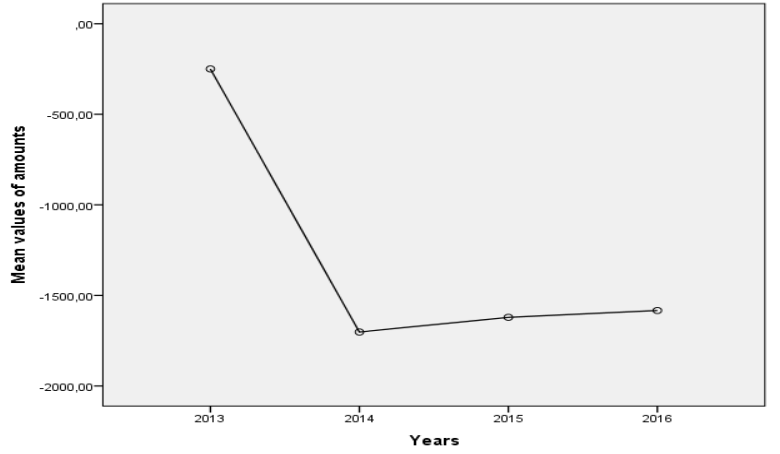

b.

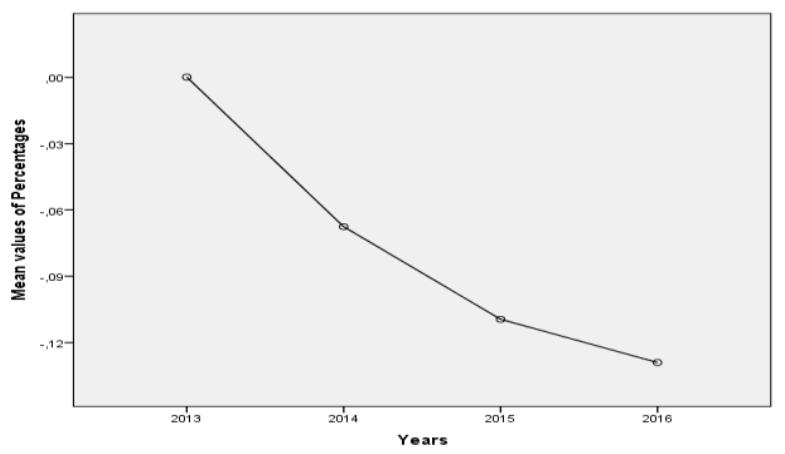

Figure 15. Profile plots of the mean values of changes of Fixed Assets the years of the period 2013-16 from AM200516 (a) in amounts and (b) in percentages. 


\section{The test of Homogeneity of Variances of the Equity}

The test of Homogeneity of Variances of the Equity for the years of the time period 2013-16 and the AM2005-16 showed that there are no significant differences between the variances of the five variables (or groups of the amounts of Equity) (Levene Statistic $=0.725$, Sig.=0.575). The one-way ANOVA showed that there are no statistically significant differences between the mean values of the five variables $(\mathrm{F}=0.218$, Sig. $=0.928)$. Figure 16 gives the profile plot of the mean values of the five variables.

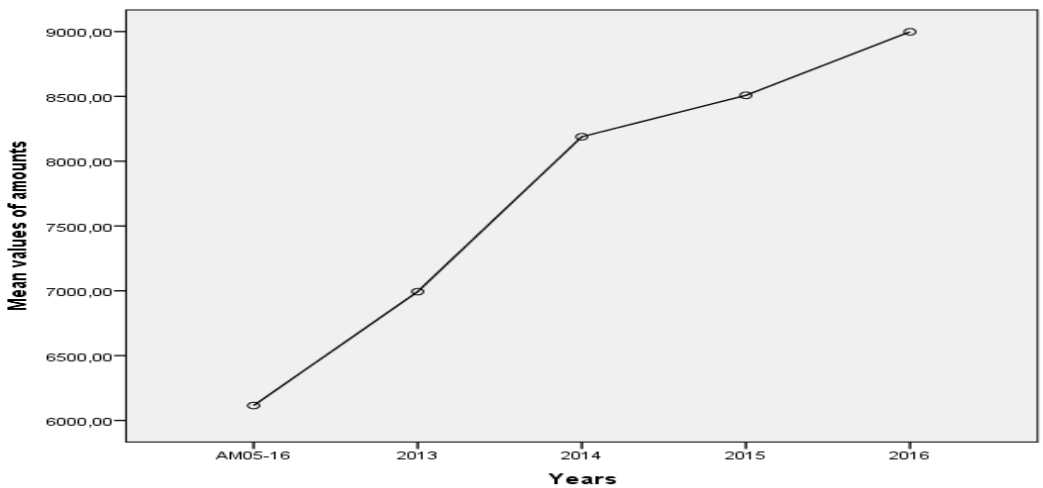

Figure 16. Profile plot of the mean values of the amounts of Equity the years of the period 2013-16 and of the AM2005-16.

The test of Homogeneity of Variances of the changes of the Equity in the time periods 2013-14, 2014-15 and 2015-16 inform us that there are no significant differences between the variances of the amounts changes (Levene Statistic $=2.102$, Sig. $=0.125)$ but the variances in the percentage changes differ $($ Levene Statistic $=3.907$, Sig. $=0.022)$. Since the post hoc test for variables with different variances (Games-Howell test) showed that the mean values of the four variables do not differ by two, we can accept the results of the analysis of variance. The one-way ANOVA showed that there are no statistically significant differences between the mean values of the three variables for both the changes in amounts and in percentages, $(\mathrm{F}=2.102$, Sig. $=0.696)$ and $(\mathrm{F}=0.947$, Sig. $=0.390)$ respectively. Figure 17 gives the profile plots of the mean values of the three variables (a) for amounts and (b) for percentages.

a.

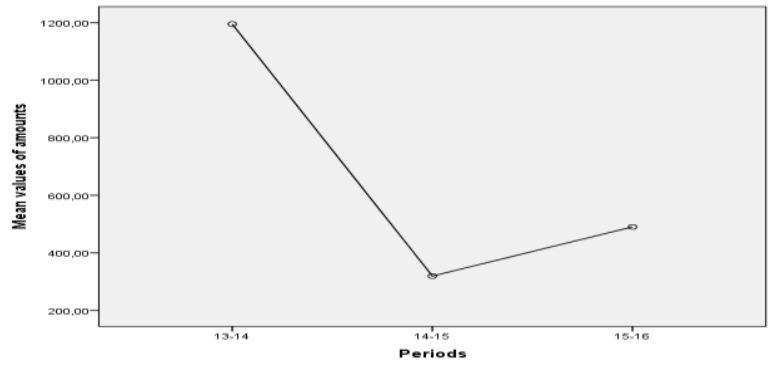

b.

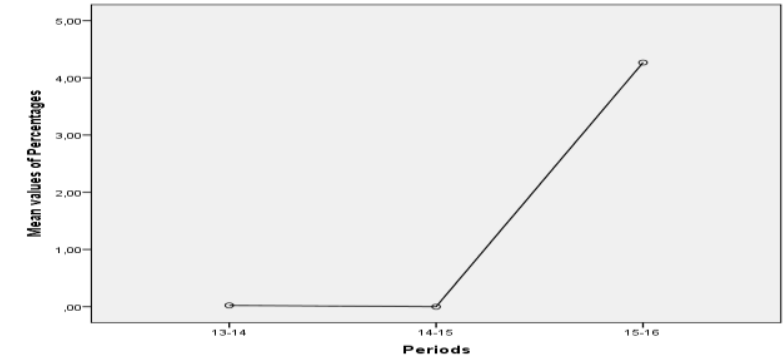

Figure 17. Profile plots of the mean values of the changes of Equity the time periods 2013-14, 2014-15 and 2015-16 (a) in amounts and (b) in percentages.

The test of Homogeneity of Variances of the changes of the Equity for the years of the time period 2013-16 from the AM2005-16 (four variables) showed that there are no significant differences between the variances of the four variables both for the changes in amounts and in percentages, $($ Levene Statistic $=1.412$ Sig. $=0.240)$ and $($ Levene Statistic $=1.494$, Sig. $=0.217)$ respectively. The one-way ANOVA showed that there are no statistically significant differences between the mean values of the four variables for both the changes in amounts and in percentages, $(\mathrm{F}=0.460$, Sig. $=0.711)$ and $(\mathrm{F}=1.299$, Sig. $=0.275)$ respectively. Figure 18 gives the profile plots of the mean values of the four variables (a) for amounts and (b) for percentages.

a.

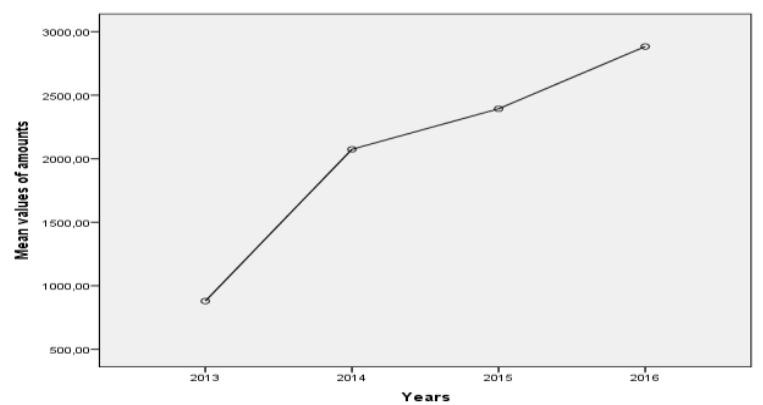

b.

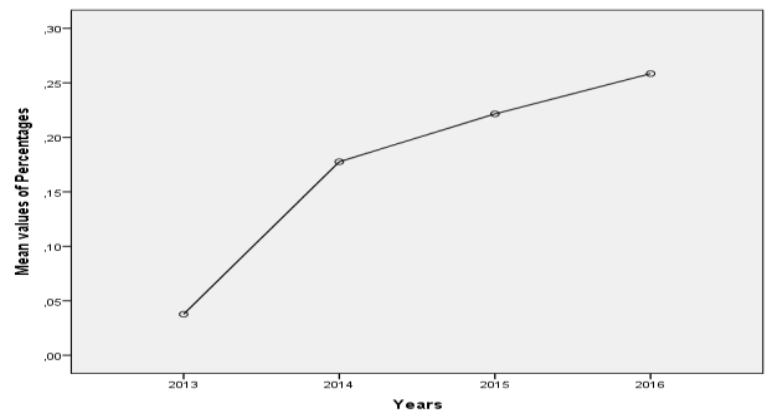

Figure 18. Profile plots of the mean values of changes of Equity the years of the period 2013-16 from AM2005-16 (a) in amounts and (b) in percentages. 


\section{The test of Homogeneity of Variances of the L/M Debts}

The test of Homogeneity of Variances of the L/M Debts for the years of the time period 2013-16 and the AM2005-16 showed that there are no significant differences between the variances of the five variables (or groups of the amounts of L/M Debts) (Levene Statistic $=0.432$, Sig.=0.785). The one-way ANOVA showed that there are no statistically significant differences between the mean values of the five variables $(\mathrm{F}=0.112$, Sig. $=0.978)$. Figure 19 gives the profile plot of the mean values of the five variables.

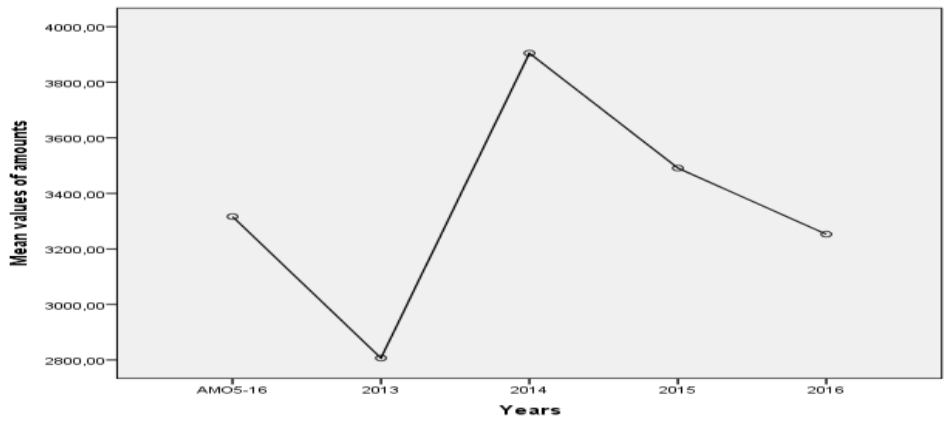

Figure 19. Profile plot of the mean values of the amounts of L/M Debts the years of the period 2013-16 and of the AM2005-16.

The test of Homogeneity of Variances of the changes of the L/M Debts in the time periods 2013-14, 2014-15 and 2015-16 showed that there are no significant differences between the variances of the three variables for the changes in amounts and for those in percentages we are at the limit, (Levene Statistic $=0.591$, Sig. $=0.555)$ and $($ Levene Statistic $=3.074, \mathrm{Sig}=0.049)$ respectively. The one-way ANOVA showed that there are no statistically significant differences between the mean values of the three variables for both the changes in amounts and in percentages, $(\mathrm{F}=1.438$, Sig. $=0.240)$ and $(\mathrm{F}=1.078$, Sig.=0.343) respectively. Since the post hoc test for variables with different variances (Games-Howell test) showed that the mean values of the four variables do not differ by two, we can accept for both the changes in amounts and in percentages the results of the analysis of variance. Figure 20 gives the profile plots of the mean values of the three variables (a) for amounts and (b) for percentages.

a.

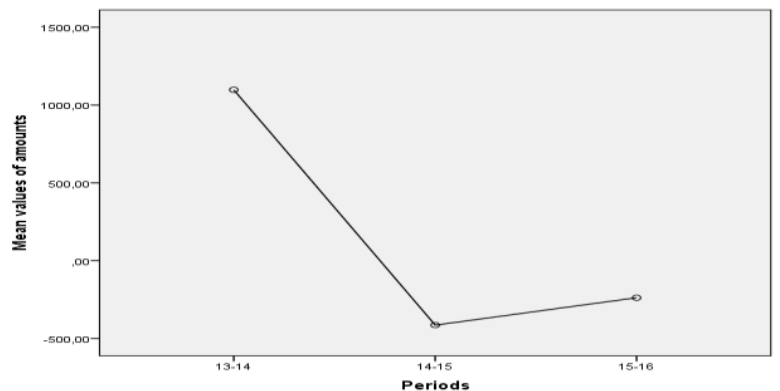

b.

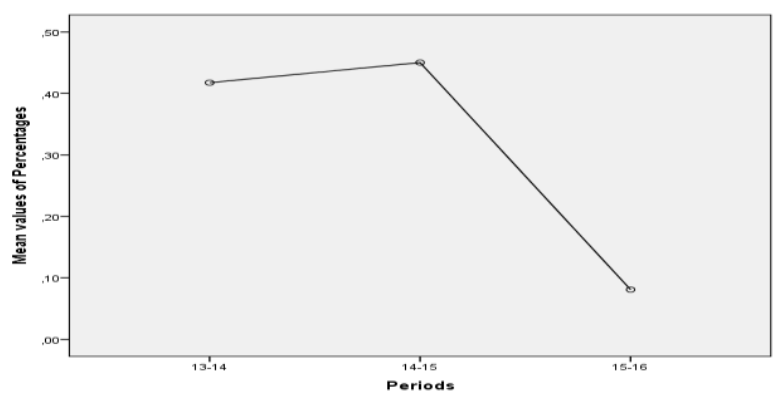

Figure 20. Profile plots of the mean values of the changes of L/ M Debts the time periods 2013-14, 2014-15 and 2015-16 (a) in amounts and (b) in percentages.

The test of Homogeneity of Variances of the changes of the L/M Debts for the years of the time period 2013-16 from the AM2005-16 (four variables) showed that there are no significant differences between the variances of the four variables for the changes in amounts (Levene Statistic $=0.548$, Sig. $=0.650$ ) but the variances in percentage changes differ (Levene Statistic $=3.091$, Sig.=0.028). The one-way ANOVA showed that there are no statistically significant differences between the mean values of the four variables for the changes in amounts $(\mathrm{F}=0.793$, Sig.=0.499). In the case of the percentages, the one-way ANOVA showed that the mean values of the four variables present significant differences $(\mathrm{F}=3.932$, Sig.=0.009). Post hoc test for variables with different variances (GamesHowell test) inform us that the mean value of percentage changes of the year 2013 from AM2005-16 differs significantly from those of the years 2015 and 2016. Figure 21 gives the profile plots of the mean values of the four variables (a) for amounts and (b) for percentages. 
a.

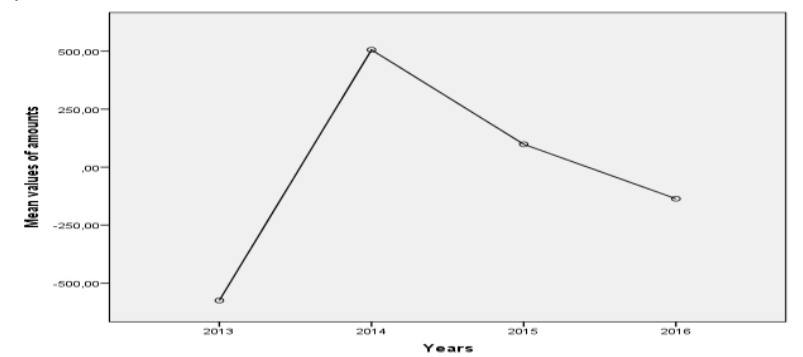

b.

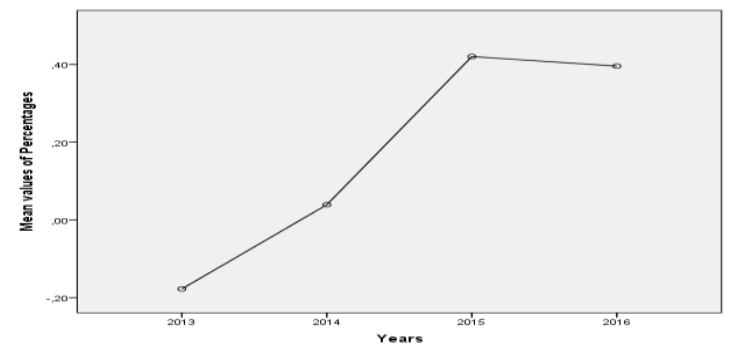

Figure 21. Profile plots of the mean values of changes of L/ M Debts the years of the period 2013-16 from AM200516 (a) in amounts and (b) in percentages.

\section{The test of Homogeneity of Variances of Sales}

The test of Homogeneity of Variances of Sales for the years of the time period 2013-16 and the AM2005-16 showed that there are no significant differences between the variances of the five variables (or groups of the amounts of Sales) (Levene Statistic $=0.399$, Sig.=0.809). The one-way ANOVA showed that there are no statistically significant differences between the mean values of the five variables $(\mathrm{F}=0.165$, Sig. $=0.956)$. Figure 22 gives the profile plot of the mean values of the five variables.

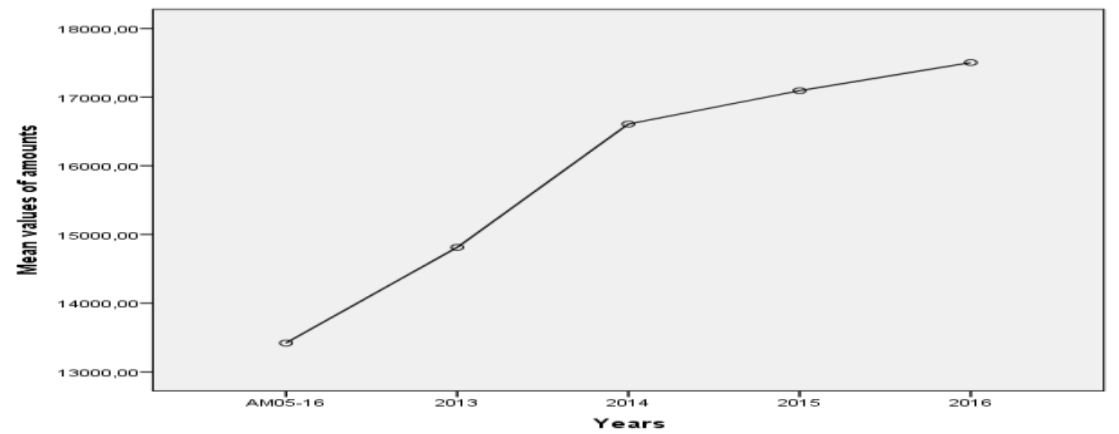

Figure 22. Profile plot of the mean values of the amounts of Sales the years of the period 2013-16 and of the AM2005-16.

The test of Homogeneity of Variances of the changes of Sales in the time periods 2013-14, 2014-15 and 2015-16 showed that there are no significant differences between the variances of the three variables both for the changes in amounts and in percentages, (Levene Statistic $=1.516$, Sig. $=0.222$ ) and (Levene Statistic $=0.195$, Sig. $=0.823$ ) respectively. The one-way ANOVA showed that there are no statistically significant differences between the mean values of the three variables for both the changes in amounts and in percentages, $(\mathrm{F}=0.932$, Sig. $=0.396)$ and $(\mathrm{F}=2.212$, Sig. $=0.112)$ respectively. Figure 23 gives the profile plots of the mean values of the three variables (a) for amounts and (b) for percentages.

a.

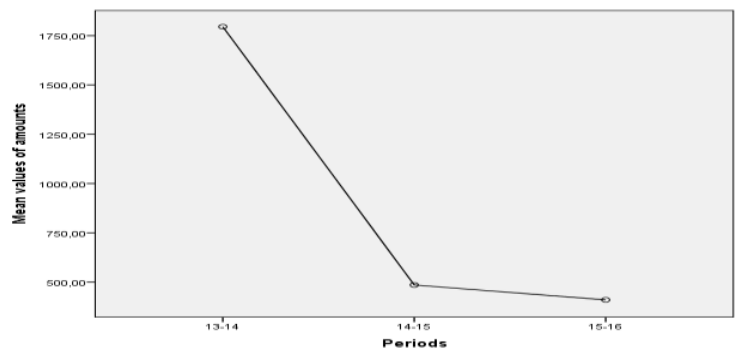

b.

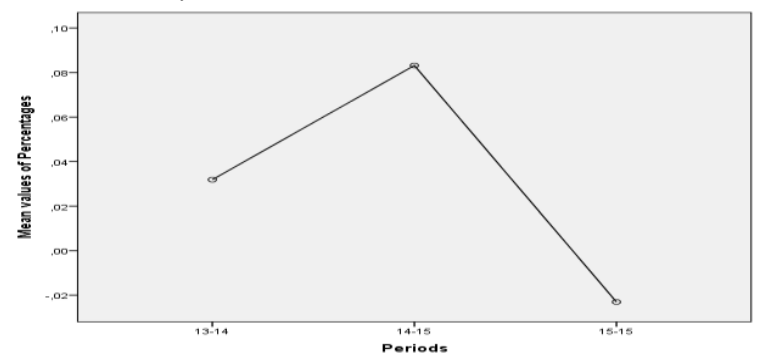

Figure 23. Profile plots of the mean values of the changes of Sales the time periods 2013-14, 2014-15 and 2015-16 (a) in amounts and (b) in percentages.

The test of Homogeneity of Variances of the changes of Sales for the years of the time period 2013-16 from the AM2005-16 (four variables) showed that there are no significant differences between the variances for the changes in the amounts (Levene Statistic $=2.018$, Sig. $=0.112$ ) but the variances in the percentage changes differ (Levene Statistic $=4.968$, Sig.=0.002). The one-way ANOVA showed that there are no statistically significant differences between the mean values of the four variables for both the changes in amounts and percentages, $(\mathrm{F}=0.722, \mathrm{Sig} .=0.540)$ and $\mathrm{F}=0.940$, Sig. $=0.422$ ) respectively. Since the post hoc test for variables with different variances (Games-Howell test) showed that the mean values of the four variables do not differ by two, we can accept the results of the variance analysis. Figure 24 gives the profile plots of the mean values of the four variables (a) for amounts and (b) for percentages. 
a.

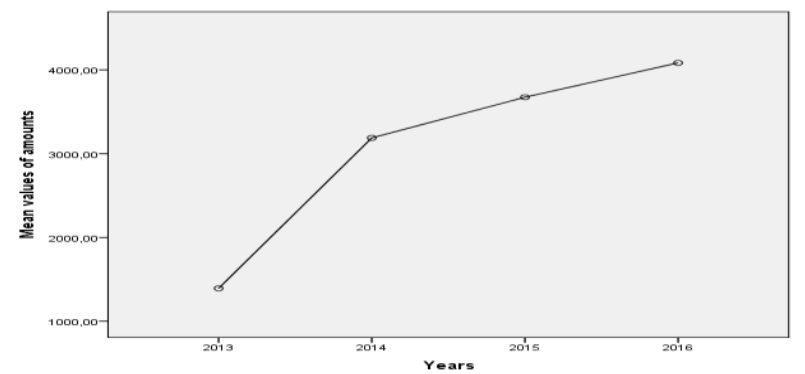

b.

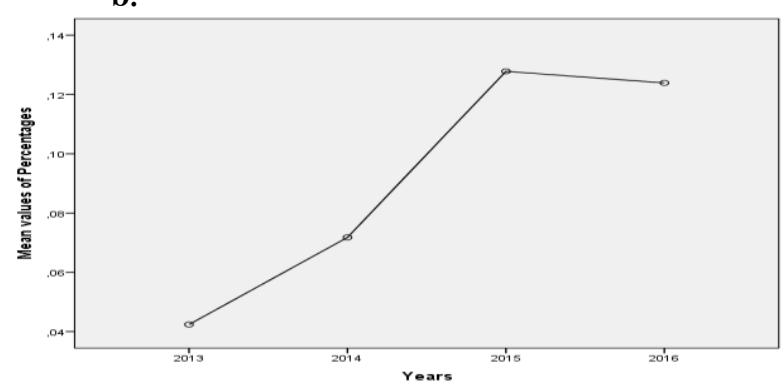

Figure 24. Profile plots of the mean values of changes in Sales the years of the period 2013-16 from AM2005-16 (a) in amounts and $(b)$ in percentages.

\section{The test of Homogeneity of Variances of the Gross profit}

The test of Homogeneity of Variances of the Gross profit for the years of the time period 2013-16 and the AM2005-16 showed that there are no significant differences between the variances of the five variables (or groups of the amounts of Gross profit) (Levene Statistic $=0.399$, Sig. $=0.809$ ). The one-way ANOVA showed that there are no statistically significant differences between the mean values of the five variables $(F=0.165$, Sig. $=0.956)$. Figure 25 gives the profile plot of the mean values of the five variables.

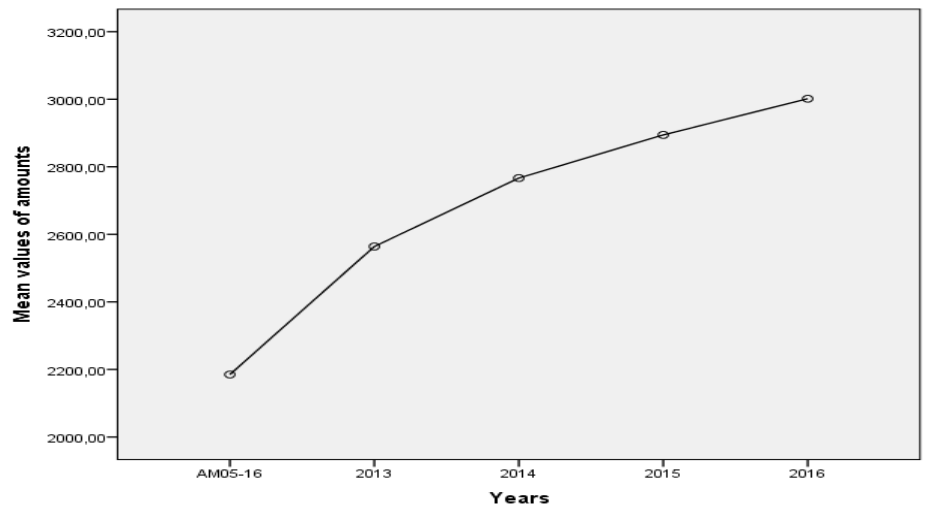

Figure 25. Profile plot of the mean values of the amounts of Gross profit the years of the period 2013-16 and of the AM2005-16.

The test of Homogeneity of Variances of the changes of the Gross profit in the time periods 2013-14, 2014-15 and 2015-16 showed that there are no significant differences between the variances of the three variables both for the changes in amounts and in percentages, (Levene Statistic $=1.516$, Sig. $=0.222$ ) and $($ Levene Statistic $=0.195$, Sig.=0.823) respectively. The one-way ANOVA showed that there are no statistically significant differences between the mean values of the three variables for both the changes in amounts and percentages, $(F=0.932$, Sig. $=0.396)$ and $(\mathrm{F}=2.212$, Sig. $=0.112)$ respectively. Figure 26 gives the profile plots of the mean values of the three variables (a) for amounts and (b) for percentages.

a.
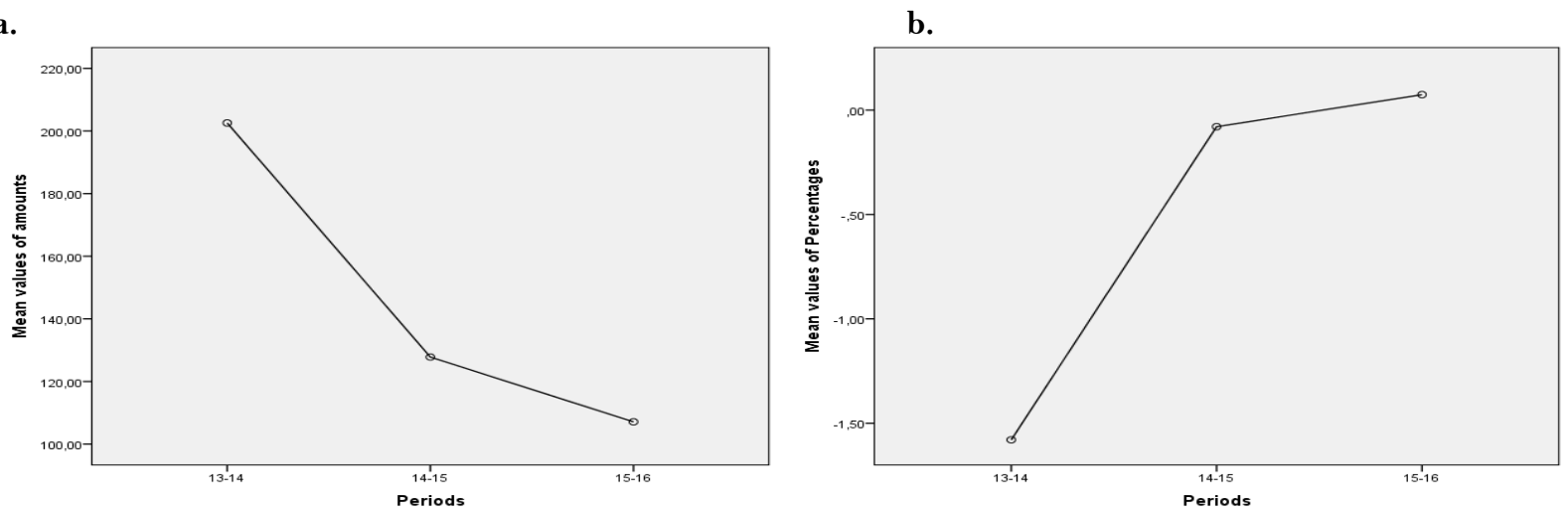

Figure 26. Profile plots of the mean values of the changes of Gross profit the time periods 2013-14, 2014-15 and 2015-16 (a) in amounts and (b) in percentages.

The test of Homogeneity of Variances of the changes of Gross profit for the years of the time period 2013-16 from the AM2005-16 (four variables) showed that there are no significant differences between the variances of the changes in the amounts (Levene Statistic $=2.018$, Sig. $=0.112$ ) but the variances in the percentage changes differ (Levene 
Statistic $=4.968$, Sig.=0.002). The one-way ANOVA showed that there are no statistically significant differences between the mean values of the four variables for both the changes in amounts and percentages, $(\mathrm{F}=0.722, \mathrm{Sig} .=0.540)$ and $\mathrm{F}=0.940$, Sig. $=0.422$ ) respectively. Since the post hoc test for variables with different variances (Games-Howell test) showed that the mean values of the four variables do not differ by two, we can accept the results of the variance analysis. Figure 27 gives the profile plots of the mean values of the four variables (a) for amounts and (b) for percentages.

a.

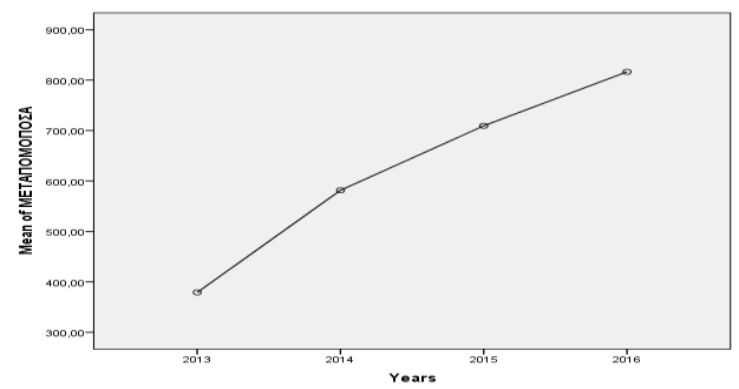

b.

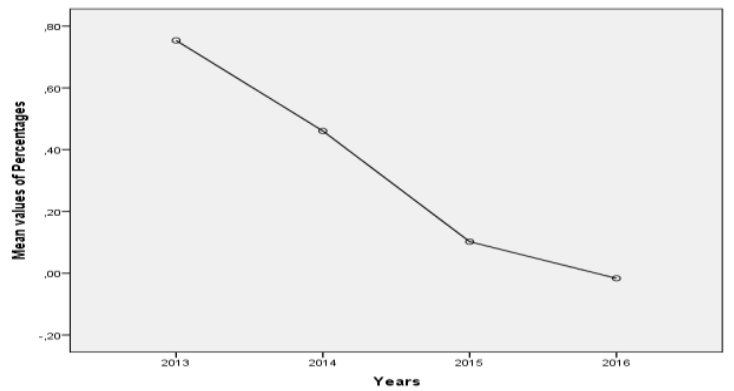

Figure 27. Profile plots of the mean values of changes of Gross profit the years of the period 2013-16 from AM200516 (a) in amounts and (b) in percentages.

\section{The test of Homogeneity of Variances of the Profit before Tax}

The test of Homogeneity of Variances of the Profit before Tax for the years of the time period 2013-16 and the AM2005-16 showed that there are no significant differences between the variances of the five variables (or groups) (Levene Statistic $=1.574$, Sig.=0.181). The one-way ANOVA showed that there are no statistically significant differences between the mean values of the five variables $(\mathrm{F}=0.637 \mathrm{Sig} .=0.536)$. Figure 28 gives the profile plot of the mean values of the five variables.

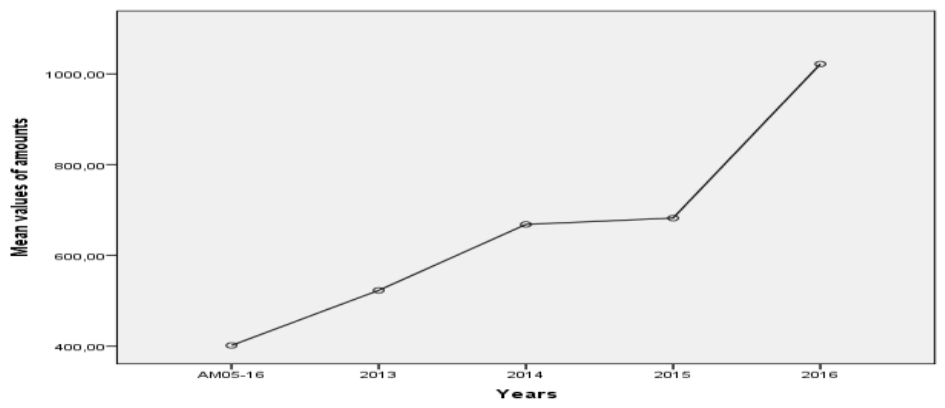

Figure 28. Profile plot of the mean values of the amounts of Profit before Tax the years of the period 2013-16 and of the AM2005-16.

The test of Homogeneity of Variances of the changes of the Profit before Tax in the time periods 2013-14, 2014-15 and 2015-16 showed that there are no significant differences between the variances of the three variables both for the changes in amounts and in percentages, (Levene Statistic = 0,512 Sig.=0,600) and (Levene Statistic $=0.437$ Sig. $=0.647)$ respectively. The one-way ANOVA showed that there are no statistically significant differences between the mean values of the three variables for both the changes in amounts and in percentages, $(\mathrm{F}=0.487, \mathrm{Sig} .=0.616)$ and $(\mathrm{F}=1.624$, Sig. $=0.200)$ respectively. Figure 29 gives the profile plots of the mean values of the three variables $(\mathrm{a})$ for amounts and (b) for percentages.

a.

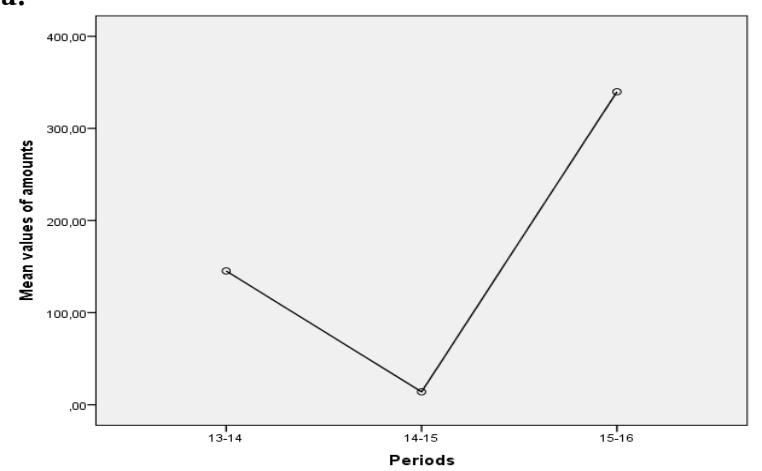

b.

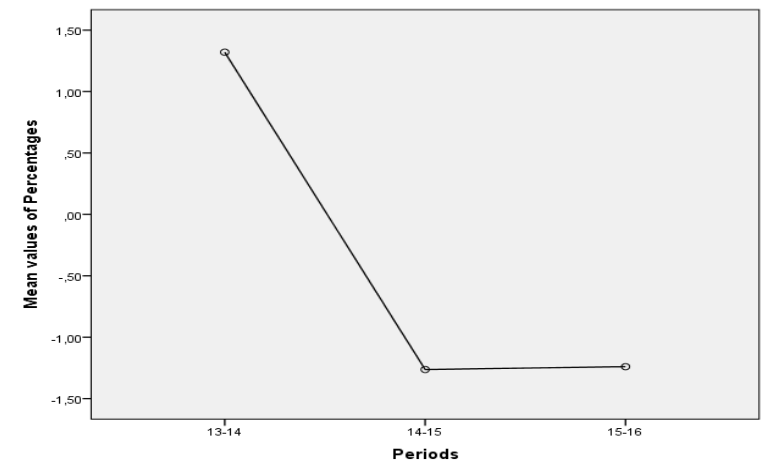

Figure 29. Profile plots of the mean values of the changes of Profit before Tax the time periods 2013-14, 2014-15 and 2015-16 (a) in amounts and (b) in percentages. 
The test of Homogeneity of Variances of the changes of the Profit before Tax for the years of the time period 2013-16 from the AM2005-16 (four variables) showed that there are no significant differences between the variances of the four variables both for the changes in amounts and in percentages, (Levene Statistic $=2.294$, Sig. $=0.079$ ) and (Levene Statistic $=0.555$, Sig. $=0.645$ respectively. The one-way ANOVA showed that there are no statistically significant differences between the mean values of the four variables for both the changes in amounts and in percentages, $(\mathrm{F}=1.098$, Sig. $=0.351)$ and $\mathrm{F}=1.078$, Sig. $=0.359)$ respectively. Figure 30 gives the profile plots of the mean values of the four variables (a) for amounts and (b) for percentages.

a.

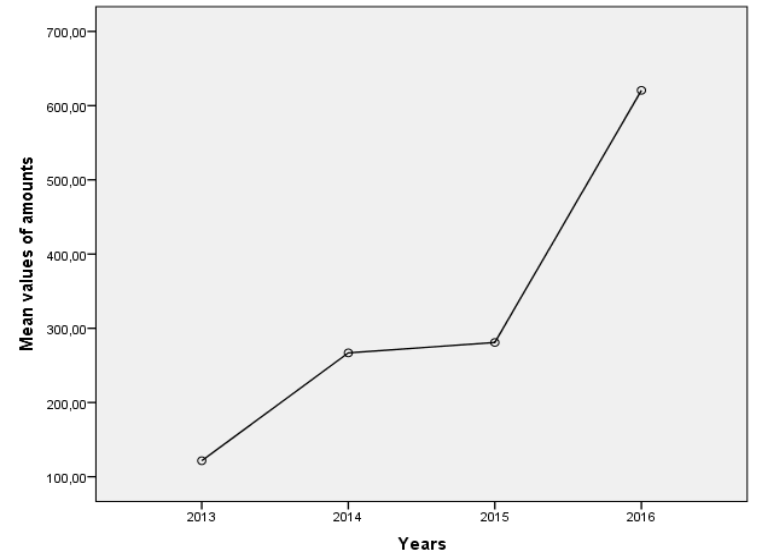

b.

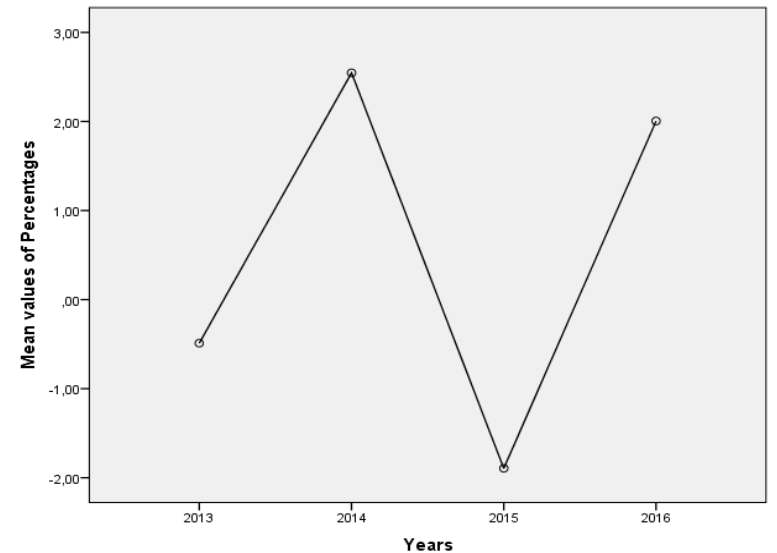

Figure 30. Profile plots of the mean values of changes of Profit before Tax the years of the period 2013-16 from AM2005-16 (a) in amounts and (b) in percentages.

\section{The test of Homogeneity of Variances of the Taxes}

The test of Homogeneity of Variances of the Taxes for the years of the time period 2013-16 and the AM2005-16 showed that there are significant differences between the variances of the five variables (or groups of the amounts of Taxes) (Levene Statistic = 4,065, Sig.=0,003). The one-way ANOVA showed that there are no statistically significant differences between the mean values of the five variables $(\mathrm{F}=1.365$, Sig.=0.246). Since the post hoc test for variables with different variances (Games-Howell test) showed that the mean values of the five variables do not differ by two, we can accept the results of the variance analysis. Figure 31 gives the profile plot of the mean values of the five variables.

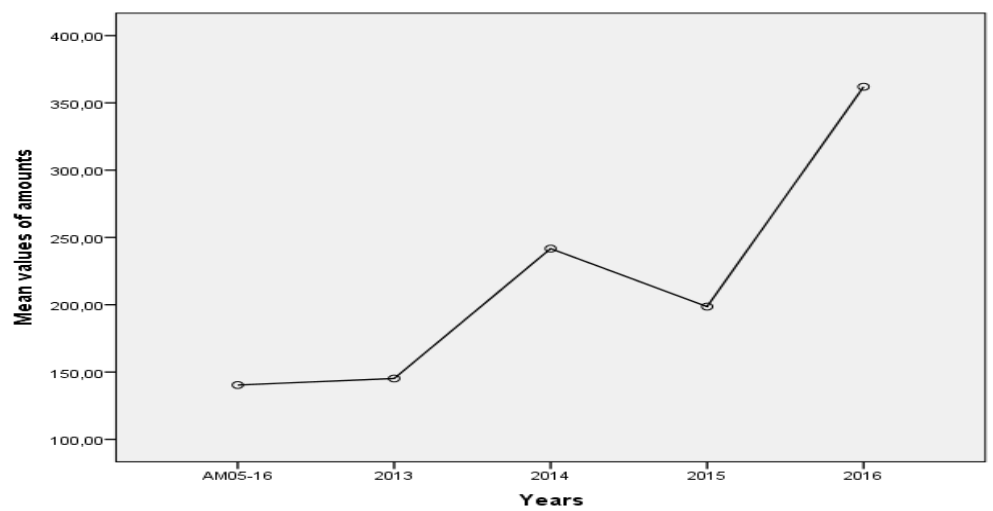

Figure 31. Profile plot of the mean values of the amounts of Taxes the years of the period 2013-16 and of the AM2005-16.

The test of Homogeneity of Variances of the changes of the Taxes in the time periods 2013-14, 2014-15 and 201516 showed that there are no significant differences between the variances of the three variables both for the changes in amounts and in percentages, (Levene Statistic $=0.705$, Sig.=0.495) and (Levene Statistic $=1.395$ Sig. $=0.250$ ) respectively. The one-way ANOVA showed that there are no statistically significant differences between the mean values of the three variables for both the changes in amounts and in percentages, $(\mathrm{F}=2.091$, Sig. $=0.126)$ and $(\mathrm{F}=0.155$, Sig. $=0.857$ respectively. Figure 32 gives the profile plots of the mean values of the three variables (a) for amounts and (b) for percentages. 
a.

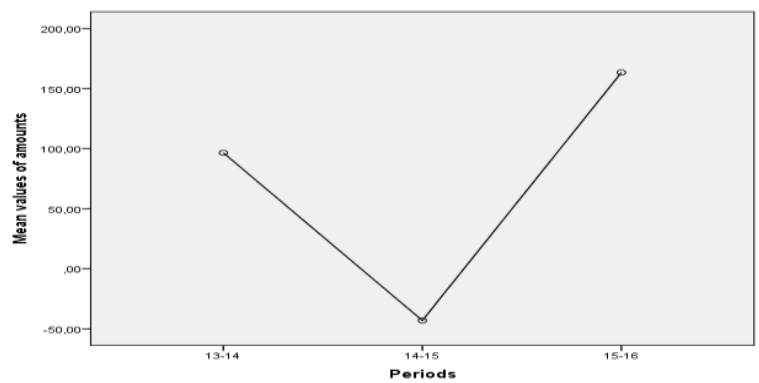

b.

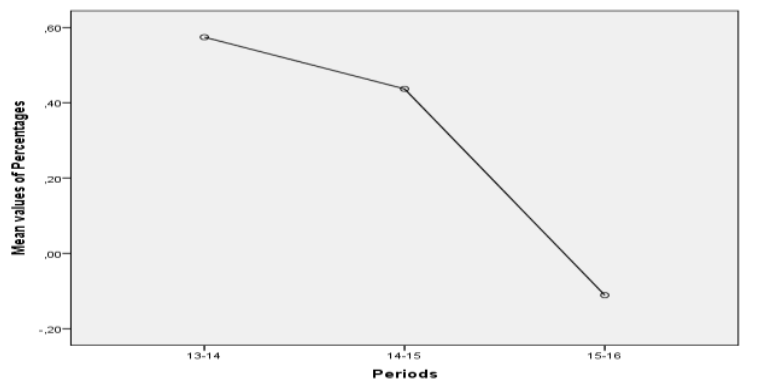

Figure 32. Profile plots of the mean values of the changes of Taxes the time periods 2013-14, 2014-15 and 2015-16 (a) in amounts and (b) in percentages.

The test of Homogeneity of Variances of the changes of the Taxes for the years of the time period 2013-16 from the AM2005-16 (four variables) showed that there are significant differences between the variances of the changes in the amounts (Levene Statistic $=4.583$, Sig.=0.004) but the variances of the changes in the percentages do not differ significantly (Levene Statistic $=2.004$, Sig.=0.114). The one-way ANOVA showed that there are no statistically significant differences between the mean values of the four variables for both the changes in amounts and in percentages, $(\mathrm{F}=1.365$, Sig. $=0.246)$ and $(\mathrm{F}=1.175$, Sig. $=0.320)$ respectively. Since the post hoc test for variables with different variances (Games-Howell test) showed that the mean values of the changes in amounts do not differ by two, we can accept the results of the variance analysis. Figure 33 gives the profile plots of the mean values of the four variables (a) for amounts and (b) for percentages.

a.

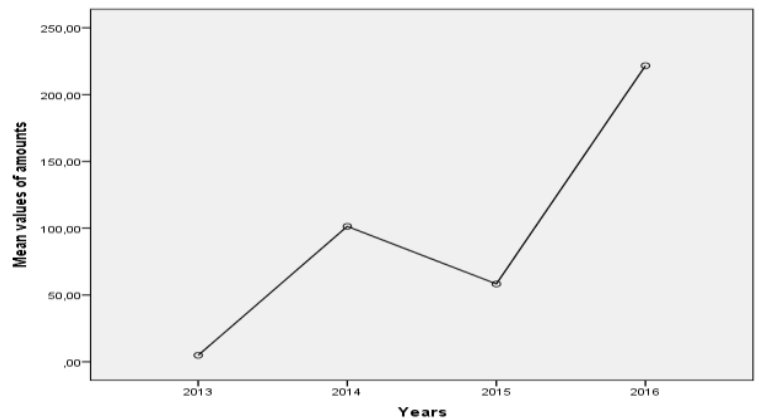

b.

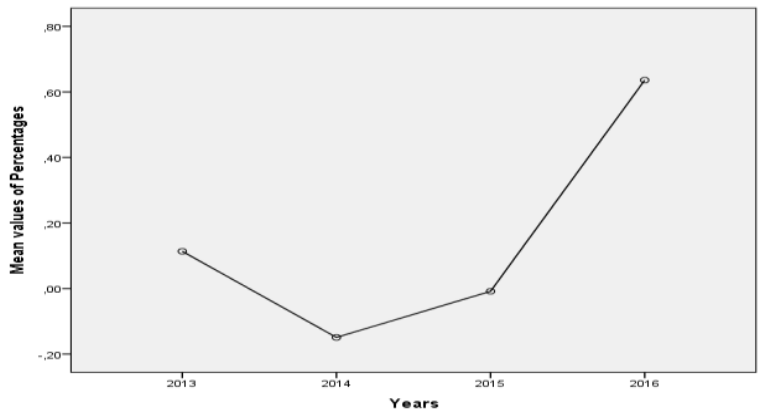

Figure 33. Profile plots of the mean values of changes of Taxes the years of the period 2013-16 from AM2005-16 (a) in amounts and (b) in percentages.

\section{The test of Homogeneity of Variances of the Net Profit after taxes}

The test of Homogeneity of Variances of the Net Profit for the years of the time period 2013-16 and the AM200516 showed that there are no significant differences between the variances of the five variables (or groups of the amounts of Net Profit) (Levene Statistic $=1.265$, Sig.=0.284). The one-way ANOVA showed that there are no statistically significant differences between the mean values of the five variables $(\mathrm{F}=0.127$, Sig. $=0.973)$. Figure 34 gives the profile plot of the mean values of the five variables.

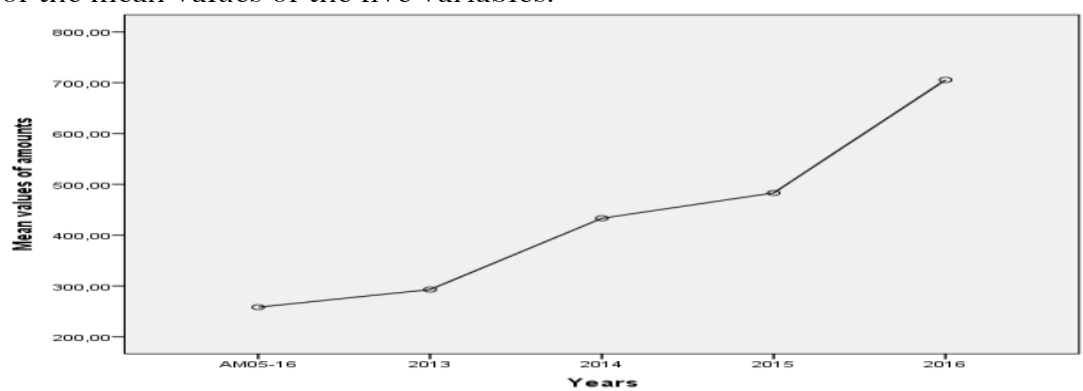

Figure 34. Profile plot of the mean values of the amounts Net Profit after taxes the years of the period 2013-16 and of the AM2005-16.

The test of Homogeneity of Variances of the changes of the Net Profit after taxes in the time periods 2013-14, 2014-15 and 2015-16 showed that there are no significant differences between the variances of the three variables both for the changes in amounts and in percentages, (Levene Statistic $=0.355$, Sig.=0.702) and (Levene Statistic $=$ 1.229, Sig.=0.295) respectively. The one-way ANOVA showed that there are no statistically significant differences between the mean values of the three variables for both the changes in amounts and in percentages, $(\mathrm{F}=0.233$, Sig. $=0.792)$ and $(\mathrm{F}=1.253$, Sig. $=0.288)$ respectively. Figure 35 gives the profile plots of the mean values of the three variables (a) for amounts and (b) for percentages. 
a.

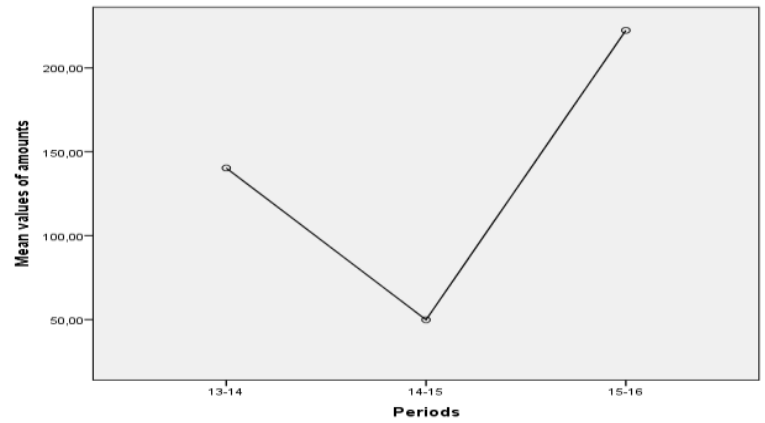

b.

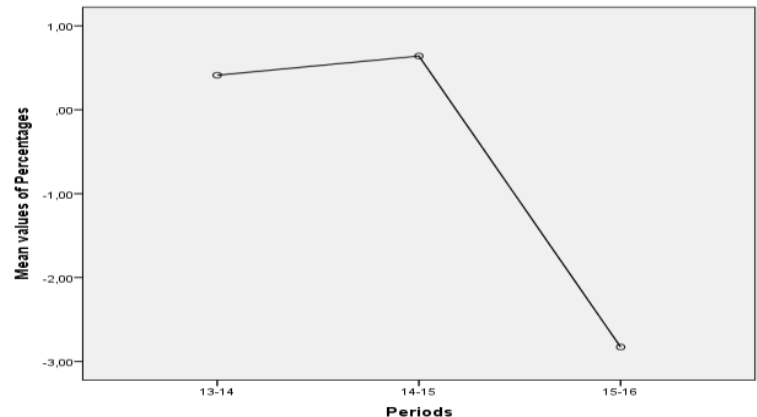

Figure 35. Profile plots of the mean values of the changes of Net Profit after taxes the time periods 2013-14, 2014-15 and 2015-16 (a) in amounts and (b) in percentages.

The test of Homogeneity of Variances of the changes of the Net Profit after taxes for the years of the time period 2013-16 from the AM2005-16 (four variables) showed that there are no significant differences between the variances of the changes in the amounts (Levene Statistic $=1.114$, Sig. $=0.344$ ) but the variances in the percentages changes differ $($ Levene Statistic $=6.965$, Sig.=0.000). The one-way ANOVA showed that there are no statistically significant differences between the mean values of the four variables for both the changes in amounts and in percentages, $(\mathrm{F}=0.125, \mathrm{Sig} .=0.293)$ and $\mathrm{F}=0.642$, Sig. $=0.589)$ respectively. Since the post hoc test for variables with different variances (Games-Howell test) showed that the mean values of the four variables do not differ by two, we can accept the results of the variance analysis. Figure 36 gives the profile plot of the mean values of the four variables (a) for amounts and (b) for percentages.

a.

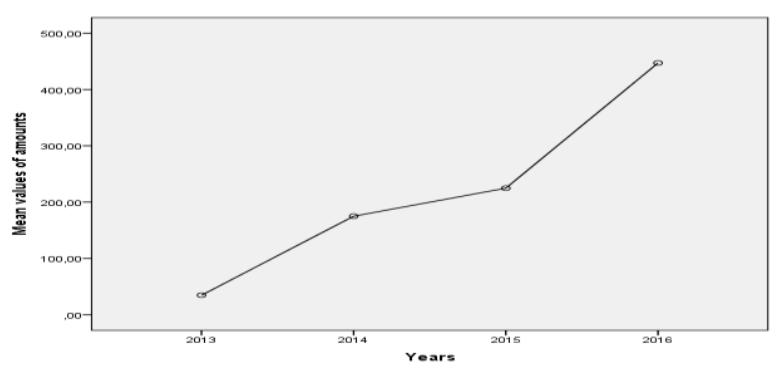

b.

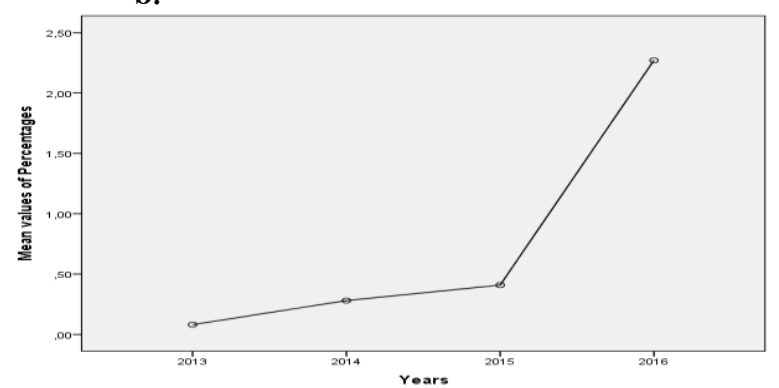

Figure 36. Profile plots of the mean values of changes of Net Profit after taxes the years of the period 201316 from AM2005-16 (a) in amounts and (b) in percentages.

\section{Conclusions}

The changes in amounts of the Total Assets in the time period 2014-15 are small and concentrated around zero. The percentage changes of the Total Assets in 2013 from the AM2005-16 shows the highest normality and concentration around zero. The variance of the changes in percentages of the fixed assets in the years of the period 2013-16 from the AM2005-16 increases from 2013 to 2016 and is accompanied by the appearance of outliers.

The percentage changes in Equity for the periods 2013-14, 2014-15 and 2015-16 are not significant except for the change in the capital of a company in the period 2015-16, which increased by $275.23 \%$. During the period 2013-15, there was a significant increase in the L/M Debt for some companies. The percentage changes in the L/M Debt of the companies the years of the period 2013-16 from AM2005-06 are on the rise, and this is due to the fact that some companies have significantly increased their L/M Debt.

In the period 2014-15, some companies experienced a significant increase in Sales. The sales of many companies shifted to worse compared to AM2005-16, as we ascend the scale of years of the 2013-16 period. The percentage changes in Gross Profit the years of the period 2013-16 are quite limited, with the exception of one company showing a significant increase in Gross Profit in 2013-14 (from -3 to 284). Almost uniform percentage changes had Gross Profit the years of the period 2013-16 from AM2005-16 with very few outliers. A roughly similar picture to Gross Profit shows the percentage changes in Profit before Tax for the period 2013-16, except for a few extreme cases. The same image presents the percentages changes in the Profit before Tax the years 2013-16 from the AM2005-16.

In the year 2016, there are significant changes in the relevant taxes and a positive change (increase) from the AM2005-16. The largest percentage of changes in net profit are recorded in the period 2015-16. In 2016, there are, in many companies, significant changes in Net Profit from AM2005-16, both positive and negative. The one-way ANOVA showed that for the Total Assets, Fixed Assets, Equity, M/L Debt, Sales, Gross Profit, Profit before Tax, Taxes and Net Profit there are not statistically significant differences between the mean values of the amounts for the years of the time period 2013-16 and the AM2005-16.

The analysis of variance showed that for the Total Assets, Fixed Assets, Equity, L/M Debt, Sales, Gross Profit, Profit before Tax, Taxes and Net Profit, the mean values of the changes both in amounts and in percentages for the DOI: 10.25103/ijbesar.122.05 
time periods 2013-14, 2014-15 and 2015-16 do not show significant differences at level of 5\%. In addition, the analysis of variance showed that the mean values of the changes in Total Assets, Fixed Assets, Equity, Sales, Gross Profit, Profit before Tax, Taxes and Net Profit the years 2013, 2014, 2015 and 2016 from AM2005-16 do not present significant differences at level of $5 \%$ for both amounts and percentages. The analysis of variance showed that the mean values of the amounts changes in the L/M Debt the years 2013, 2014, 2015 and 2016 from AM2005-16 do not show significant differences at the level of $5 \%$. However, the mean values of the percentage changes in the L/M Debt the year 2013 from AM2005-16 differ significantly from those of the years 2015 and 2016 from AM2005-16. In short, we can say that the percentage changes in Total Assets and Equity the time period 2013-16 are small and concentrated around zero. The same period, we have a significant increase in L/M Debt and Sales, except for a few extreme cases, while the percentage changes in Gross Profit and Profit before Tax are limited. The year 2016 there were significant changes in Taxes and Net Profit from AM2005-16.

The present paper and the available data allow each candidate researcher to continue working by analyzing various ratios. In addition, the work may be extended by studying the evolution of the financial statement items, distinguishing the companies in small medium and large on the basis of Total Assets, Fixed Assets, Equity, Net Debt, Sales or Gross Profit.

\section{Acknowledgement:}

1. The present research was financed by the authors: Rigas Ioannis, Pantos Nikolaos, Rigas Nikolaos, Goulas Apostolos, Karelakis Christos and Theodossiou George.

2. Senior authorship is shared.

\section{References}

Artelaris., P., 2017, “Geographies of crisis in Greece: A social well-being approach” Geoforum, Volume 84, Pages 5969. http://dx.doi.org/10.1016/j.geoforum.2017.06.003

BANK OF GREECE 2009, "SUMMARY OF THE ANNUAL REPORT 2008”, Presented to the General Meeting of Shareholders by Governor George Provopoulos. ISSN $1105 \quad-\quad 0527$. https://www.bankofgreece.gr/BogEkdoseis/Summary_Annrep2008.pdf

Bondonio, D. \& Greenbaum, R., 2007, "Do local tax incentives affect economic growth? What mean impacts miss in the analysis of enterprise zone policies", Regional Science and Urban Economics, Volume 37 (1), 121-136.

Bronzini, R. \& Di Blasio, G., 2006, 'Evaluating the impact of investment incentives: the case of Italy's Law 488/1992, Journal of Urban Economics, Volume 60 (2), 327-349.

Cabral, R., Castellanos-Sosa, F., A., 2019, "Europe's income convergence and the latest global financial crisis", Research in Economics, Volume 73 23-34. https://doi.org/10.1016/j.rie.2019.01.003.

Carlucci, C. \& Pellegrini, G., 2005,” Nonparametric analysis of the effects on employment of public subsidies to capital accumulation: the case of law 488/92 in Italy", Presented at the Congress AIEL 2004, Modena.

Chatzitheodoridis F., Kontogeorgos, A., Liltsi P., Apostolidou I., Michailidis, A. and Loizou E.,2016 "Small Women's Cooperatives in less favoured and mountainous areas under economic instability”, Agricultural Economics Review, Volume .17 (1). https://econpapers.repec.org/article/agsaergaa/262883.htm

Chekimoglou, E., Roupa, E. (2006) "History of the Food Industry", Book, Edit. Kerkira (in Greek).

Criscuolo, C., Martin, R., Overman, H. \& Van Reenen, J., 2009, “The Causal Effects of an Industrial Policy” LSE, manuscript. https://www.nber.org/papers/w17842.pdf

Daly, M., Gorman I., Lenjosek, G., MacNevin A, \& Phiriyapreunt, W. (1993). The impact of regional investment incentives on employment and productivity”, Regional Science and Urban Economics, Volume 23, 559-575.

Dias Claudia S.L., Ricardo Gouveia Rodrigues, João J. Ferreira, 2019, "What's new in the research on agricultural entrepreneurship?, Journal of Rural Studies, Volume 65; 99-115. https://doi.org/10.1016/j.jrurstud.2018.11.003.

Economic Bulletin, Ministry of Finance, 2018, Council of Economic Advisors, Hellenic Republic. Issue 5, September 19; $\quad$ Retrieved from https://www.enterprisegreece.gov.gr/assets/content/files/c11/a1750/f60/Economic_Bulletin_5-MoFGreece.pdf

European Commission. "Internal Market, Industry, Entrepreneurship, and SMEs Food and drink industry" https://ec.europa.eu/growth/sectors/food/competitiveness_en. (Access 14-4-2019)

FAO (2017). World's future food security "in jeopardy" due to multiple challenges, the report warns. http://www.fao.org/news/story/en/item/471169/icode/

Foundation For Economic \& Industrial Research (IOBE) 2018. “FOOD AND DRINKS INDUSTRY. FACTS \& FIGURES” $14^{\text {th }}$ edition, $\quad$ Retrieved from http://iobe.gr/docs/research/RES_05_B_05042019_REP_GR.pdf. (Access 14-4-2019)

Foundation for Economic and Industrial Research, 2011, "The Greek Economy 4/11". Quarterly Bulletin No 66, December; Retrieved from http://iobe.gr/docs/economy/en/ECO_Q4_11_REP_ENG.pdf (Access 14-42019) 
Gabe, T.M. \& Kraybill, D., 2002, "The effects of state economic development incentives on employment growth of establishments", Journal of Regional Science, Volume 42, $703-730$. https://onlinelibrary.wiley.com/doi/abs/10.1111/1467-9787.00278

Germanoloudis, C., 2017, “Fulfillment of the objectives of Development Law 3299/04 (B phasis) from its implementation in the Region of Thessaly ". University of Thessaly. Volos Greece. http://ir.lib.uth.gr/bitstream/handle/11615/47990/16313.pdf?sequence=1\&isAllowed=y (in Greek)

Glaeser, E.L. \& Edward, L., 2001, “The economics of location-based tax incentives”, Discussion paper No. 1932, Harvard Institute of Economic Research. http://scholar.harvard.edu/files/glaeser/files/hier 1932.pdf\%3Fm=1360042861

Harris, R. \& Trainor, M., 2005, "Capital subsidies and their impact on total factor productivity: Firm-level evidence from Northern Ireland”, Journal of Regional Science, Volume 45,(1),49-74. https://onlinelibrary.wiley.com/doi/epdf/10.1111/j.0022-4146.2005.00364.x

Hellenic Federation of Enterprises (SEV), 2017, “Top Priorities. Food and Beverages" https://en.sev.org.gr/business_priorities/sector-specific-policies/\#top-priorities/

Hellenic Statistical Authority, 2018 http://www.statistics.gr/en/home/

IBM SPSS Statistics 23.

Ikonomou C., 2018, "The great Greek crisis". Book chapter "Funding the Greek Crisis. The European Union, Cohesion Policies, and the Great Recession“, Pages 1-71 https://doi.org/10.1016/B978-0-12-814566-1.00001-X

Kontogeorgos A., Pendaraki, K., Chatzitheodoridis, F., 2017, "Economic crisis and firms' performance: Empirical evidence for the Greek Cheese industry" Revista Galega de Economia, Volume $26 \quad-173$. https://dialnet.unirioja.es/ejemplar/478960 [accessed Apr 13 2019].

Lee, J.W., 1996, “Government intervention and productivity growth" Journal of Economic Growth 1, 391-414 https://link.springer.com/content/pdf/10.1007\%2FBF00141045.pdf

Loizou, E., Karelakis, C., Galanopoulos K., Mattas, K., 2019, "The role of agriculture as a development tool for a regional economy”, Agricultural Systems. Volume 173, July 2019, Pages 482-490. https://doi.org/10.1016/j.agsy.2019.04.002

Louzis, D. P., Vouldis, A. T., \& Metaxas, V. L., 2012, "Macroeconomic and Bank-Specific Determinants of NonPerforming Loans in Greece: A Comparative Study of Mortgage, Business, and Consumer Loan Portfolios”, Journal of Banking and Finance, Volume 36(4), 1012-1027. https://doi.org/10.1016/j.jbankfin.2011.10.012

Manifava, D., 2015, "The crisis has "eliminated" more than 200,000 Small and Medium-sized Enterprises from the trade maps", $\quad$ Newspaper $\quad$ Kathimerini. Retrieved http://www.kathimerini.gr/814601/article/oikonomia/epixeirhseis/h-krishe3afanise-apo-ton-xarth--toyemporioy-panw-apo-200000-mme (in Greek)

Mattas K., Loizou E. and Tzouvelekas V., 2006, "Agro-food Linkages in Rural Areas: An Empirical Evaluation of Integrated Development Programs" Proceedings of the OECD workshop entitled "Coherence of Agricultural and Rural Development Policies", OECD publications.

Norman, L., and Ranciere, R., 2006, "Financial Development, Financial Fragility, and Growth“. Journal of Money, Credit, and Banking, Volume 38, 4: 1051-1076. https://muse.jhu.edu/ (accessed April 11, 2019).

Parliament of the Hellenic Republic 2016, "Explanatory Report of the Draft Law 4133/2016" https://www.hellenicparliament.gr/UserFiles/c8827c35-4399-4fbb-8ea6-aebdc768f4f7/9606840.pdf

Polychronidou, P., Florou, G., and Karasavvoglou, A., 2016, "Consequences of the economic crisis to consumer behaviour in Greece - an empirical analysis”, International Journal of Applied Management Science, 8, 2, 163-182.

Saba, I. (2012). “Determinants of Non Performing Loans: Case of US Banking Sector” Economic, Volume 44(3), 81121. http://www.rejournal.eu/article/determinants-non-performing-loans-case-us-banking-sector

Schalk, H.J. \& Untied, G., 2000, "Regional investment incentives in Germany: impacts on factor demand and growth" Annals of Regional Sciences, Volume $173-195$. https://link.springer.com/content/pdf/10.1007\%2Fs001689900008.pdf [Access Sept.30, 2018]

Stournaras, I., 2018, "Four Pillars to Address NPLs at NPL" Summit 2018: Red Loans - Openings \& Society" Retrieved from https://www.bankofgreece.gr/Pages/el/Bank/News/default.aspx https://doi.org/10.1016/j.jbankfin.2011.10.012

Stratou, A. (2013). “ Strategic Business Analysis: Case Study Mediterranean Foods AE ", University of Piraeus, Library http://dione.lib.unipi.gr/xmlui/handle/unipi/6142

Voumvaki, Jessie, 2018, “The Effects of Economic Crisis on Greek Entrepreneurship” London School of Economics and Political Science, https://blogs.lse.ac.uk/greeceatlse/2018/02/01/greek-entrepreneurship/ (Access 10-42019). 